\title{
The unique geomorphology and physical properties of the Vestalia Terra plateau
}

\author{
D.L. Buczkowski ${ }^{\mathrm{a}, *}$, D.Y. Wyrick ${ }^{\mathrm{b}}$, M. Toplis ${ }^{\mathrm{c}}$, R.A. Yingst ${ }^{\mathrm{d}}$, D.A. Williams ${ }^{\mathrm{e}}$, W.B. Garry ${ }^{\mathrm{f}}$, S. Mest ${ }^{\mathrm{d}}$, \\ T. Kneissl ${ }^{g}$, J.E.C. Scully ${ }^{\text {h }}$, A. Nathues ${ }^{i}$, M.C. De Sanctis ${ }^{j}$, L. LeCorre ${ }^{i}$, V. Reddy ${ }^{i}$, M. Hoffmann ${ }^{i}$, \\ E. Ammannito ${ }^{g}$, A. Frigeri ${ }^{j}$, F. Tosi ${ }^{j}$, F. Preusker ${ }^{\mathrm{k}}$, T. Roatsch ${ }^{\mathrm{k}}$, C.A. Raymond ${ }^{\mathrm{l}}$, R. Jaumann ${ }^{\mathrm{k}}$, \\ C.M. Pieters ${ }^{\mathrm{m}}$, C.T. Russell ${ }^{\mathrm{h}}$
}

a JHU-APL, Laurel, MD 21045, USA

${ }^{\mathrm{b}}$ SwRI ${ }^{\circledR}$, San Antonio, TX 78238, USA

' IRAP, Observatoire Midi Pyrénées, University of Toulouse, 31400 Toulouse, France

' PSI, Tucson, AZ 85719, USA

e ASU, Tempe, AZ 85004, USA

${ }^{\mathrm{f}}$ Goddard Space Flight Center, Greenbelt, MD 20771, USA

${ }^{\mathrm{g}}$ Freie Universitaet Berlin, Berlin, Germany

${ }^{\mathrm{h}}$ UCLA, Los Angeles, CA 90095, USA

${ }^{\mathrm{i}}$ Max Planck Institute, Katlenburg-Lindau, Germany

${ }^{\mathrm{j}}$ INAF-IAPS, Rome, Italy

${ }^{\mathrm{k}}$ DLR, Berlin, Germany

${ }^{1}$ JPL, California Institute of Technology, Pasadena, CA 91109, USA

${ }^{\mathrm{m}}$ Brown University, Providence, RI 02912, USA

\section{A R T I C L E I N F O}

\section{Article history:}

Received 17 May 2013

Revised 11 March 2014

Accepted 19 March 2014

Available online 4 April 2014

\section{Keywords:}

Asteroid Vesta

Geological Processes

Tectonics

Volcanism

Impact Processes

\begin{abstract}
A B S T R A C T
We produced a geologic map of the Av-9 Numisia quadrangle of asteroid Vesta using Dawn spacecraft data to serve as a tool to understand the geologic relations of surface features in this region. These features include the plateau Vestalia Terra, a hill named Brumalia Tholus, and an unusual "dark ribbon" material crossing the majority of the map area. Stratigraphic relations suggest that Vestalia Terra is one of the oldest features on Vesta, despite a model crater age date similar to that of much of the surface of the asteroid. Cornelia, Numisia and Drusilla craters reveal bright and dark material in their walls, and both Cornelia and Numisia have smooth and pitted terrains on their floors suggestive of the release of volatiles during or shortly after the impacts that formed these craters. Cornelia, Fabia and Teia craters have extensive bright ejecta lobes. While diogenitic material has been identified in association with the bright Teia and Fabia ejecta, hydroxyl has been detected in the dark material within Cornelia, Numisia and Drusilla. Three large pit crater chains appear in the map area, with an orientation similar to the equatorial troughs that cut the majority of Vesta. Analysis of these features has led to several interpretations of the geological history of the region. Vestalia Terra appears to be mechanically stronger than the rest of Vesta. Brumalia Tholus may be the surface representation of a dike-fed laccolith. The dark ribbon feature is proposed to represent a long-runout ejecta flow from Drusilla crater.
\end{abstract}

(c) 2014 Published by Elsevier Inc.

\section{Introduction}

NASA's Dawn spacecraft arrived at the Asteroid 4 Vesta on July 16, 2011, and collected imaging, spectroscopic, and elemental abundance data during its one-year orbital mission. The three instruments on Dawn used to collect these data include the

\footnotetext{
* Corresponding author.

E-mail address: debra.buczkowski@jhuapl.edu (D.L. Buczkowski).
}

Framing Camera (FC) (Sierks et al., 2011), the Visible and Infrared Spectrometer (VIR) (De Sanctis et al., 2011), and the Gamma Ray and Neutron Detector (GRaND) (Prettyman et al., 2012a). Dawn had three orbital phases at Vesta: a survey orbit at $\sim 2700 \mathrm{~km}$ altitude, a high altitude mapping orbit (HAMO) at $685 \mathrm{~km}$ altitude, and a low altitude mapping orbit (LAMO) at $200 \mathrm{~km}$ altitude.

Earth-based spectroscopic studies of Vesta (e.g. McCord et al., 1970; Gaffey, 1997) show that it has similar reflectance spectral signatures to the howardite-eucrite-diogenite (HED) meteorites 
(e.g. Drake, 1979, 2001; Consolmagno and Drake, 1977; Takeda, 1997). This indicates that the HEDs may be vestan fragments (e.g. Binzel and Xu, 1993), a fact that provided key motivation for Vesta as a target of the Dawn mission. Because of the igneous nature of these meteorites, it has been suspected that Vesta may have undergone volcanic and/or magmatic activity at some point in its history (e.g. Keil, 2002). The search for volcanic and magmatic features and description of their spatial distribution was thus an active component of Dawn's mission at Vesta.

Of the HEDs, eucrites are basaltic rocks, composed of calciumpoor pyroxene, pigeonite, and calcium-rich plagioclase (Takeda, 1997; Keil, 2002). Diogenites are also igneous rocks, dominated by magnesium-rich orthopyroxene, with small amounts of plagioclase and olivine (Takeda, 1997; Keil, 2002; Beck and McSween, 2010). Crystal size is generally larger than in basaltic eucrites suggesting that diogenites experienced slower cooling, consistent with a plutonic origin. Howardites are impact breccias comprised of fragments of eucrites and diogenites (Takeda, 1997; Keil, 2002). Based upon analysis of spectroscopic data acquired by VIR it is now established that Vesta's crust is perfectly compatible with mixtures dominated by eucritic, howarditic and diogenetic materials (De Sanctis et al., 2012a). The fact that diogenites are coarse grained and of high $\mathrm{Mg \#}$ (molar $\mathrm{Mg} /(\mathrm{Mg}+\mathrm{Fe})$ ) when compared to basaltic eucrites led to the idea that the crust of the parent body may have a simple layered structure possibly formed during cooling of a global magma ocean, with surface basaltic eucrites overlying deeper diogenites (Takeda, 1979). However, detailed study of the trace-element chemistry of diogenites suggests that their petrogenesis is more complex than that of simple early crystallization products and it has been proposed that they are possibly laterstage plutons injected into the eucrite crust (Barrat et al., 2010). Distinguishing between these two very different proposed crustal structures is thus vital toward understanding Vesta's history.

As part of the geological analysis of the surface, the Dawn Science Team produced a global geologic map of Vesta, at a scale of 1:500,000 (Yingst et al., in press) and a series of 15 quadrangle geologic maps (Fig. 1A) at a scale of 1:250,000 (Roatsch et al., 2012). Here we concentrate on our geologic analysis and mapping of Av-9 Numisia, an equatorial quadrangle that covers $216-288^{\circ} \mathrm{E}$ longitude and $\pm 22.5^{\circ}$ latitude, in the 'Claudia' coordinate system developed by the Dawn Science Team (Russell et al., 2012; Roatsch et al., 2012); this system is different from the International Astronomical Union (IAU) system for Vesta (Archinal et al., 2011). Dawn data published in the Planetary Data System (PDS) (Li, 2012) follow the IAU coordinate system recommendations but all previous published analyses of Dawn data (e.g. Russell et al., 2012; Jaumann et al., 2012; Schenk et al., 2012; De Sanctis et al., 2012a,b; Prettyman et al., 2012b, etc.) have utilized the Claudia system. Positive longitudes discussed in this paper are, at the time of this writing, offset by $150^{\circ}$ from the IAU system, in the sense that longitude $=($ IAU longitude $)-150^{\circ}$. Details about this matter are provided in the Introductory paper to this Special Issue (Williams et al., this 2014a).

\section{Data}

While the global map of Vesta (Yingst et al., in press) was produced at the HAMO resolution of $70 \mathrm{~m} /$ pixel, the quadrangle maps, such as the one presented here, are based on LAMO imagery (Roatsch et al., 2013). Clear filter (monochrome) FC LAMO images (spatial resolution of $\sim 20-25 \mathrm{~m} /$ pixel) were mosaicked (Fig. 1B) to make a base for the Av-9 Numisia quadrangle.

Analysis of the Av-9 imagery was enhanced by observation of the quadrangle's topography (Fig. 1D). A digital terrain model (DTM) of Vesta was derived from survey orbit FC data (spatial
(A)
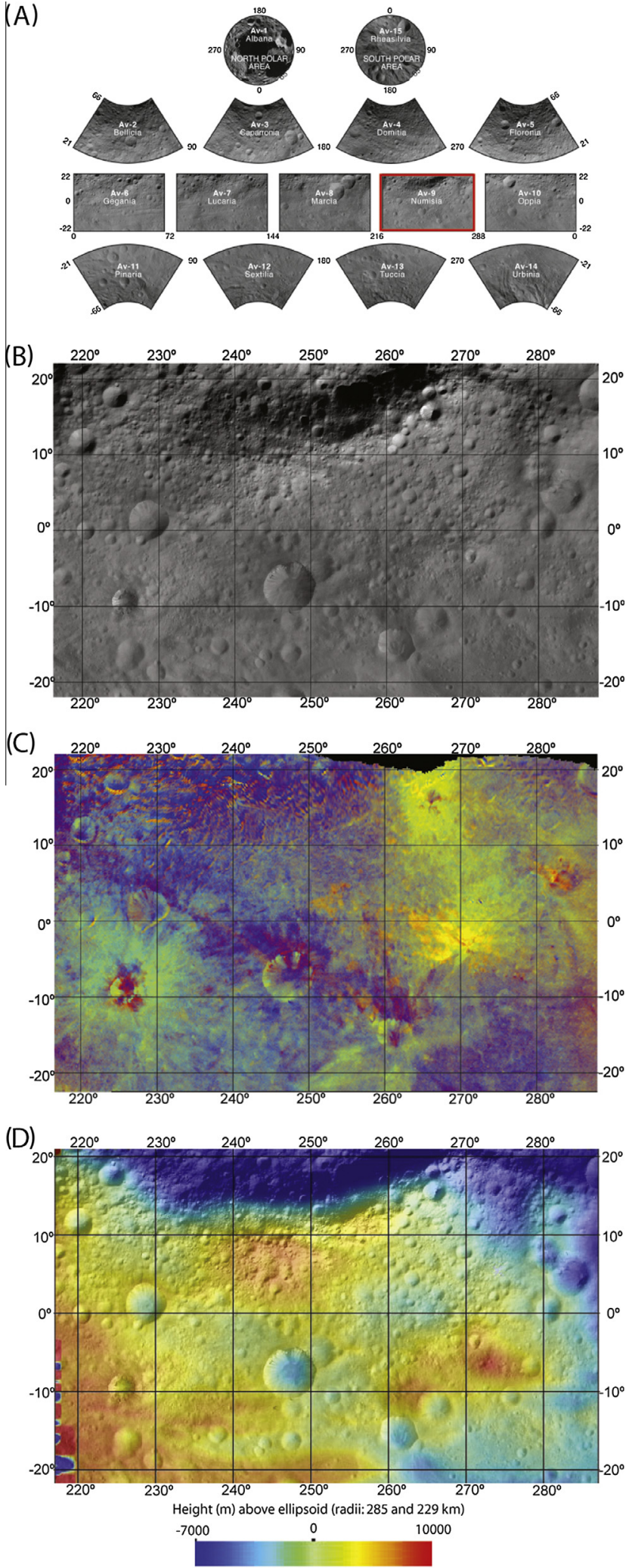

Fig. 1. (A) Vesta's quadrangle mapping schema, from Roatsch et al. (2012). (B) The FC clear filter LAMO mosaic of the Av-9 quadrangle. (C) The FC color ratio mosaic of the Av-9 quadrangle. (D) Topography of the Av-9 quadrangle. Refer to Fig. 2 for the names of major features. (For interpretation of the references to color in this figure legend, the reader is referred to the web version of this article.)

resolution of $\sim 260 \mathrm{~m} /$ pixel) (Preusker et al., 2012; Jaumann et al., 2012). This topography was continuously improved as the spatial 
resolution of the FC data steadily increased due to Dawn's threetier orbital phasing.

Variations in the surface composition of Vesta were revealed using VIR hyperspectral images from Survey ( $700 \mathrm{~m} /$ pixel) and HAMO (200 m/pixel) orbits and FC color ratio images from survey orbit (250 m/pixel) (Fig. 1C). FC color ratio images using standard Clementine ratios (Red $(750 / 430 \mathrm{~nm}) ;$ Green $(750 / 920 \mathrm{~nm})$; Blue $(430 / 750 \mathrm{~nm})$ ) (Reddy et al., 2012a) show compositional variations within the Numisia quadrangle (Fig. 1C). The spectral and compositional diversity of crater ejecta materials within the Av-9 quadrangle is illustrated by the strong variations present in the color-ratio composite image.

Evaluation of VIR data was then performed to investigate the significance of these color variations. VIR data analysis has included determining the band depths of the $1 \mu \mathrm{m}$ and $2 \mu \mathrm{m}$ absorptions associated with iron-bearing pyroxene minerals (De Sanctis et al., 2012a) and identifying deposits of hydroxyl (OH) on the asteroid (De Sanctis et al., 2012b). VIR data in the wavelength range of 3.5-5.1 $\mu \mathrm{m}$ was also utilized to determine the surface temperatures of Vesta (Tosi et al., 2013), which were then used to determine the thermal inertia (Capria et al., 2014).

\section{Geologic setting and features}

The Av-9 Numisia quadrangle is located in the equatorial region of Vesta, extending from $\pm 22.5^{\circ}$ latitude and from $216^{\circ}$ to $288^{\circ} \mathrm{E}$ longitude (Fig. 1). The map area is dominated by Vestalia Terra, an elevated plateau. Many of the impact craters in Av-9 have both bright and dark layers in their walls and also spectrally distinct ejecta lobes. Extensive compositional variations are revealed by the color ratio image (Fig. 1C). We here discuss the several noteworthy features in the Av-9 quadrangle.

\subsection{Vestalia Terra}

Vestalia Terra (Fig. 2) was recognized as a distinct region of Vesta soon after the Dawn spacecraft arrived at the asteroid and started collecting data (Jaumann et al., 2012). Both topographically high and bounded by steep scarps, Vestalia Terra can be described as a plateau that has a high albedo relative to the surrounding regions. The steep bounding scarps appear to have been formed by ancient impact events, including the Rheasilvia, Venenia, Feralia and Postumia basins (Fig. 2B). However, the Divalia Fossae troughs that cut the majority of the equatorial region of Vesta do not cut the Vestalia Terra plateau (Buczkowski et al., 2012).

Vestalia Terra is one of the largest individual features on Vesta. The area of the plateau is roughly $80,000 \mathrm{~km}^{2}$, with its east-west extent ranging from $\sim 300-430 \mathrm{~km}$ and its north-south extent ranging from $\sim 160$ to $200 \mathrm{~km}$. Although topographically high compared to surrounding terrain, there are localized topographic variations on top of the plateau (Fig. 2). The highest topography on Vesta is in the southwest portion of the plateau (Fig. 2, gray), but the plateau's interior contains some deep craters and one low intercrater area (Fig. 2, green).

\subsection{OH-bearing impact craters}

De Sanctis et al. (2012b) identified concentrations of OH on the surface of Vesta. Two regions in particular were enriched in $\mathrm{OH}$ : one which corresponds to the region of highest hydrogen concentration (to the west of Vestalia Terra) (Prettyman et al., 2012b) and the other corresponding to Oppia crater ejecta (Fig. 2B). However, three craters on Vestalia Terra were determined to have low albedo OH-enriched layers in their walls (De Sanctis et al., 2012b): Numisia, Cornelia and Drusilla craters (Fig. 2B).
(A)
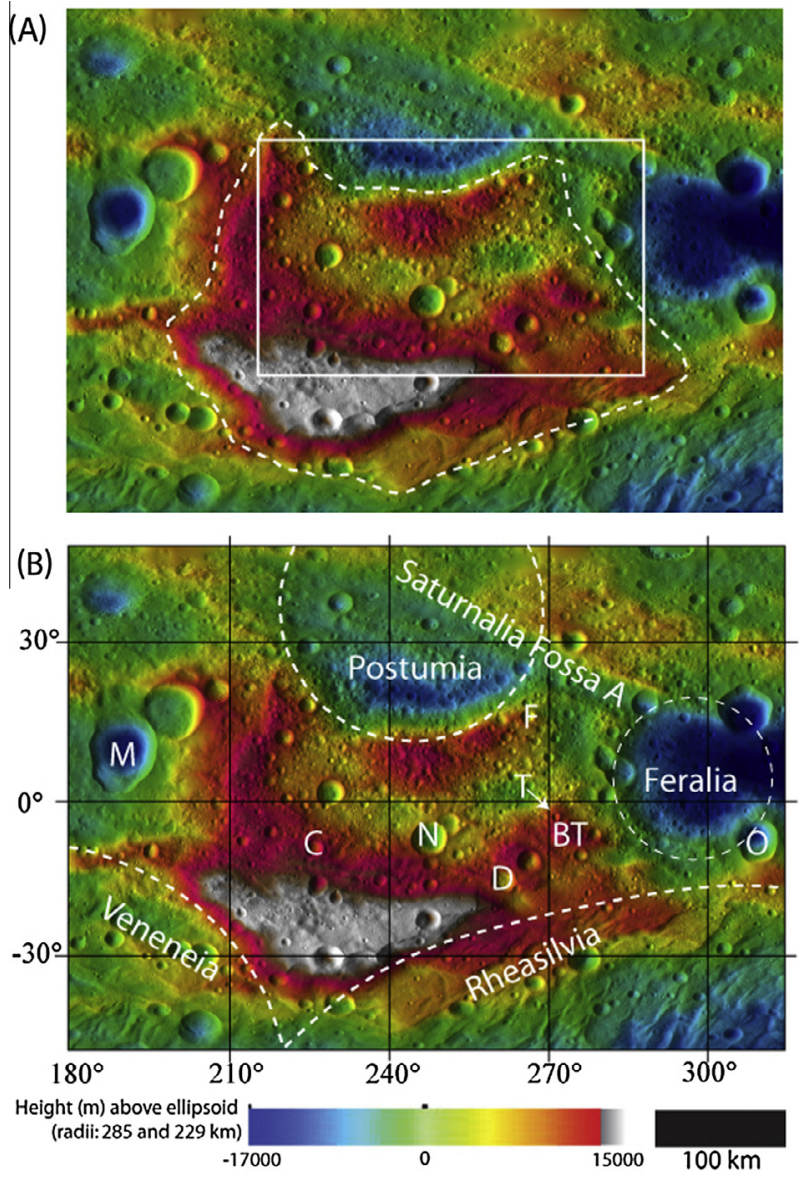

Fig. 2. A subset of global Vesta topography, showing the entire Vestalia Terra plateau. (A) Dashed line shows outline of the plateau. Solid rectangle shows the location of the Av-9 quadrangle. (B) Dashed circles show the location of the ancient basins marking the boundaries of Vestalia Terra. Saturnalia Fossa A and craters discussed in Section 3 are labeled. $\mathrm{N}=$ Numisia; $\mathrm{C}=$ Cornelia; $\mathrm{D}=$ Drusillia; $\mathrm{T}=$ Teia; F = Fabia; BT = Brumalia Tholus. Oppia (O) and Marcia (M) craters are also labeled, for reference to other analyses of Vesta.

\subsubsection{Numisia crater}

Centrally located at $7^{\circ} \mathrm{S}, 247^{\circ} \mathrm{E}$, the $33 \mathrm{~km}$ diameter Numisia crater (Fig. 3 ) is the largest impact crater in the Av-9 quadrangle. It has a sharp rim and shows both bright and dark layers in its walls. While the bright layer is evident around more than half of the Numisia rim, the dark layer is only identified in the northern third of the crater, stratigraphically above the bright layer (Fig. 3B).

The Numisia impact cuts an older crater to its northeast (Fig. 3B); this older crater appears to be buried by the linear flow of dark material described in Section 3.4. The dark material evident in the crater wall may thus be exposures of the "dark ribbon" material, as will be discussed later. However, this implies that the dark ribbon material was emplaced before the Numisia impact.

Dark material is also observed on the crater floor (Fig. 3B). $\mathrm{OH}$ detections correspond to this dark material, as well as that detected in the wall (De Sanctis et al., 2012b). The dark floor deposit is also marked by rimless pits hypothesized to have formed due to the outgassing of volatiles during the impact event (Denevi et al., 2012), suggesting that this particular dark deposit is in-place material, not a slump deposit.

\subsubsection{Cornelia crater}

Cornelia crater (Fig. 4) is a $15 \mathrm{~km}$ diameter crater located at $9.3^{\circ} \mathrm{S}$ and $225.5^{\circ} \mathrm{E}$. Although significantly smaller than Numisia, Cornelia has a more extensive and more spectrally diverse ejecta blanket. There are two distinct lobes of ejecta observable in the 
(A)

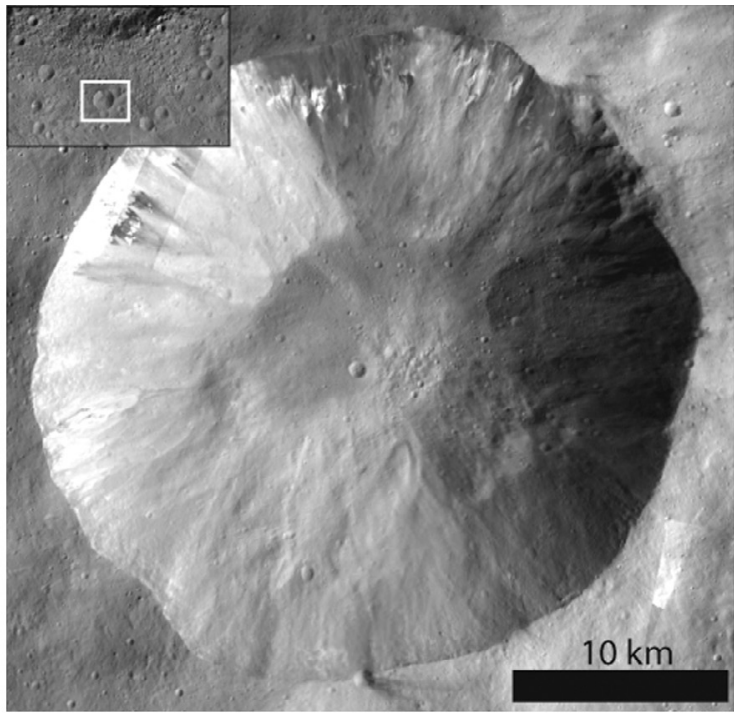

(B)

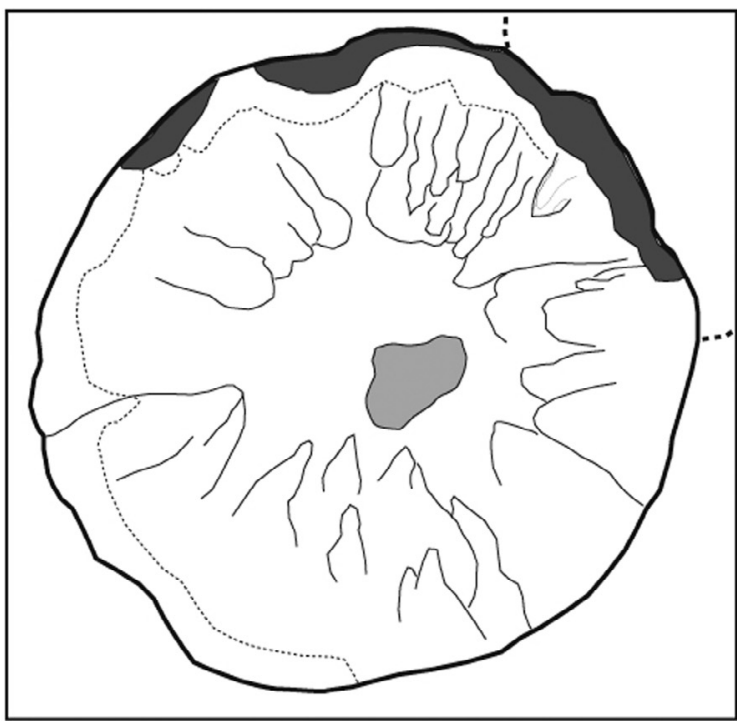

Fig. 3. (A) FC clear filter LAMO mosaic of Numisia crater. Inset box shows location of Numisia marked by white square on the Av-9 mosaic. (B) Sketch map of features found within Numisia. Thin solid lines outline some of the overlapping masswasting lobes on the walls of Numisia; only those visible at the resolution of the figure are sketched. Dark gray notes location of the dark-toned material high in the northern wall. Fine dotted lines mark the lower extent of outcrops of bright material below the dark material. The pitted terrain on the floor of the crater is light gray. Dashed lines mark the location of the older crater to the northeast of Numisia.

FC color ratio data (Fig. 1C): this two-toned ejecta is also evident in the clear filter FC data (Fig. 4A). In addition, Cornelia displays an extensive ray system that extends to the south and west beyond the boundaries of the Av-9 quadrangle.

Cornelia's interior shows both bright and dark layers, with a large deposit of low albedo material on the crater floor. As in Numisia, the $\mathrm{OH}$ detections correspond to the dark material (De Sanctis et al., 2012b) and the dark floor deposit is marked by rimless pits (Fig. 4), similar to those formed by the outgassing of volatiles during impact (Denevi et al., 2012). The Cornelia pitted terrain is more than $10^{\circ}$ colder than the surrounding terrain (Tosi et al., 2013) and has a high thermal inertia (Capria et al., 2014). This suggests that these materials have an increased density and/or thermal conductivity compared to the surrounding terrain, which is consistent with the model of pitted terrain formation due to devolatilization (Tosi et al., 2013; Capria et al., 2014). The pitted floor terrain in Cornelia is more extensive and distinct than that in
(A)

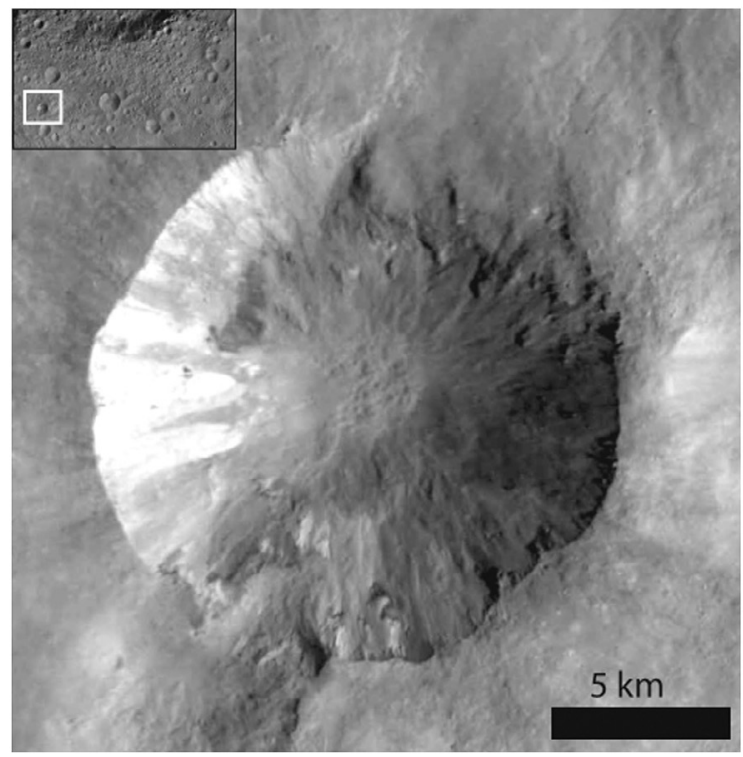

(B)

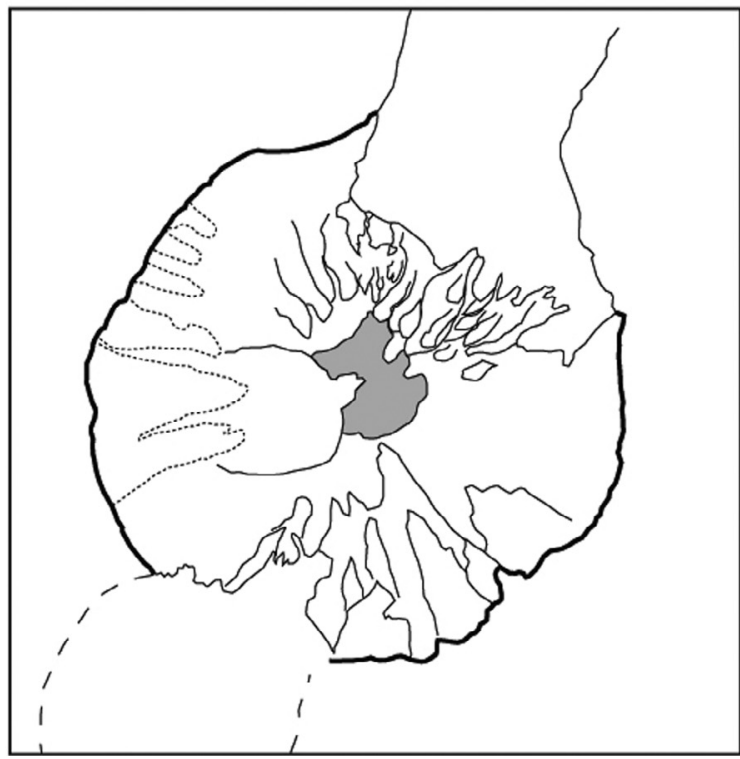

Fig. 4. (A) FC clear filter LAMO mosaic of Cornelia crater. Inset box shows location of Cornelia marked by white square on the Av-9 mosaic. (B) Sketch map of features found within Cornelia. Thin solid lines outline some of the overlapping masswasting lobes on the walls of Cornelia; only those visible at the resolution of the figure are sketched. Dotted lines mark the light-toned mass-wasting material on the western wall. The pitted terrain on the floor of the crater is shown by the solid gray area. Dashed line marks the rim of the older crater to the south of Cornelia.

Numisia (Denevi et al., 2012) and most likely is in-place material, not a slump deposit.

High-albedo mass-wasting lobes can be observed on the western wall of Cornelia, starting from the interior bright layer and extending down to cover parts of the pitted floor terrain (Fig. 4). On the north and south faces of the crater wall, mass-wasting is expressed as multiple overlapping lobes of a lower albedo material (Fig. 4); these lobes appear to be tied to regions of slope collapse of the crater rim (Fig. 4B). The south wall rim collapse occurs where Cornelia overlies an older small crater. The northern rim collapse is correlated to the northern dark ejecta flow. These mass-wasting lobes have striated surfaces.

Gully-like features that bear some resemblance to those seen on Mars have been mapped within Cornelia (Scully et al., 2014a). Models of gully formation due to the sublimation of volatiles have produced very similar features (e.g. Cedillo-Flores et al., 2011), 
which would be consistent with the observations of $\mathrm{OH}$ associated with the crater (De Sanctis et al., 2012b) and models of pitted terrain formation (Denevi et al., 2012). It has also been theorized that the Cornelia features could possibly be a result of transient liquid water flow (Scully et al., 2014a). However, similar mass-wasting lobes and gully-like features have also been successfully reproduced in models of dry granular flow on both the Moon (e.g. Bart, 2007; Senthil Kumar et al., 2013) and Mars (e.g. Shinbrot et al., 2004).

\subsubsection{Drusilla crater}

Drusilla (Fig. 5) is a $21 \mathrm{~km}$ diameter crater centered at $15.1^{\circ} \mathrm{S}$ and $261.4^{\circ} \mathrm{E}$. While a high albedo layer is evident in its walls, a darker material is identified on its floor. Although the albedo of this floor material is not as low as the floor material in Cornelia crater, it has a similar reddish-brown appearance in the FC color ratio data (Fig. 1C) and is where $\mathrm{OH}$ is detected (De Sanctis, 2012b). Unlike in Numisia crater, there is very little dark material observed in the crater wall above the bright layer.

Drusilla shows distinct differences on two opposing faces, with the division roughly described by a line crossing the crater diagonally from the northwest to the southeast (Fig. 5B). South of this dividing line the crater walls clearly show the bright

(A)

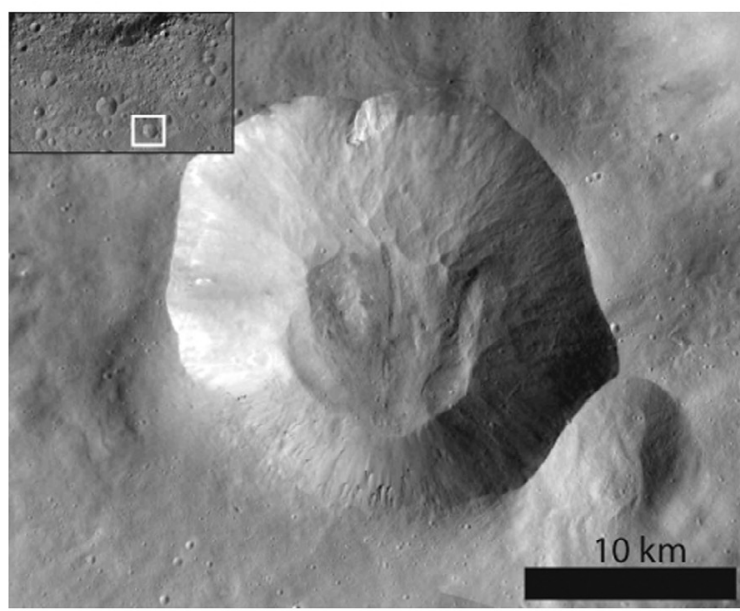

(B)

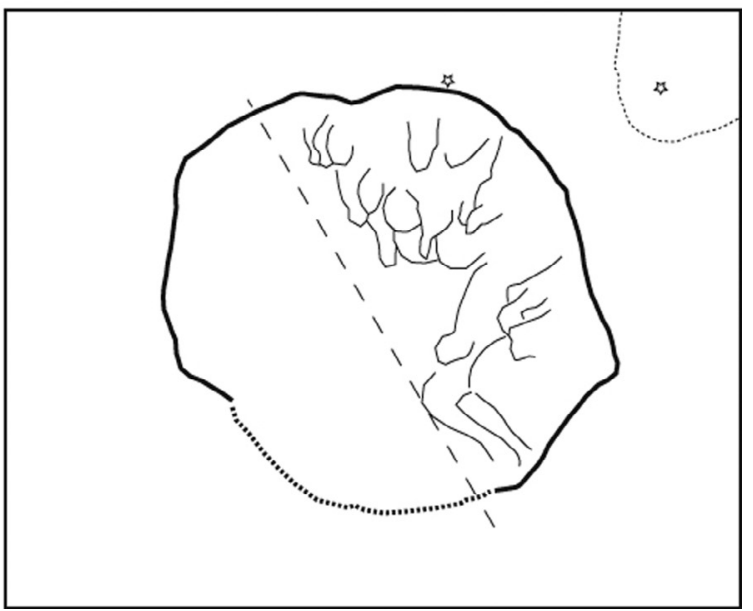

Fig. 5. (A) FC clear filter LAMO mosaic of Drusilla crater. Inset box shows location of Drusilla marked by white square on the Av-9 mosaic. (B) Sketch map of features found within Drusilla. Thin solid lines outline some of the overlapping masswasting lobes on the walls of Drusilla; only those visible at the resolution of the figure are sketched. Thick dotted line marks a less distinct portion of the crater rim. Stars indicate small craters with dark ejecta. Thin dotted line indicates bright deposit northeast of Drusilla; this material is not Drusilla ejecta. layer, as well as loose bright material lower on the wall. Boulders are evident in the southernmost part of the wall, but the crater wall in most of this region is smooth. The northern wall, however, displays overlapping lobes of mass-wasting material; some lobe fronts extend onto the crater floor. These lobes are generally smooth, although a few boulders are observed on the crater floor lobe fronts.

Drusilla's ejecta also shares this north-south dichotomy. Ejecta to the north of the crater rim is low albedo and smooth to hummocky, with striations radial to the crater center. Smaller craters that formed on this ejecta have dark floors or rays (Fig. 5B), implying that the subsurface material is darker than the surface. Ejecta to the south of the crater is high albedo, and rubbly in texture close to the rim but hummocky further away.

\subsection{Other impact craters}

\subsubsection{Teia crater}

Teia crater (Fig. 6A) is a $6.6 \mathrm{~km}$ diameter semi-circular impact structure centered at $3.4^{\circ} \mathrm{S}$ and $271.0^{\circ} \mathrm{E}$. Teia overprints an older, filled $4 \mathrm{~km}$ crater and material from this older crater appears to have slumped into Teia, altering the shape of its southern rim (Fig. 6B).

Color data from Dawn's Framing Camera (FC) instrument indicates that some ejecta from Teia have a distinct composition (Fig. 6D). The false-color orange and reds correspond to high values of the $750-\mathrm{nm} / 430-\mathrm{nm}$ reflectance ratio and are observed to directly relate to high albedo ejecta material with a smeared and flow-like texture that can be observed at LAMO resolution (Fig. 6C). Analysis of data obtained by the VIR instrument has shown that while the background Vestalia Terra material is howarditic (De Sanctis et al., 2012a,b), as is consistent with the plateau being covered by ejecta from the Rheasilvia and other large impacts, these Teia ejecta are diogenitic in composition (De Sanctis et al., 2014). In addition, thermal analysis utilizing VIR infrared data indicates that these ejecta have a higher thermal inertia and are $5 \mathrm{~K}$ cooler than the surrounding material, suggesting either a reduced local porosity, increased thermal conductivity or reduced roughness (Capria et al., 2014). A reduced roughness is consistent with the smooth and flow-like appearance of these materials (Fig. 6C).

\subsubsection{Fabia crater}

Fabia crater (Fig. 7) is a $12 \mathrm{~km}$ diameter crater at the northern edge of the Vestalia Terra plateau, centered at $15.6^{\circ} \mathrm{N}$ and $265.9^{\circ} \mathrm{E}$. Fabia has a sharp-rimmed western wall but the remaining $270^{\circ}$ of crater wall is indistinct and slumped (Fig. 7B). This kind of extreme difference in rim morphology has been theorized to be the result of impact into steep slopes and the resultant craters have been termed as "bimodal" craters (Krohn et al., 2014). There is a bright layer evident in the sharp western wall, from which gullylike features consistent with dry granular flow (e.g. Shinbrot et al., 2004; Bart, 2007; Senthil Kumar et al., 2013; Scully et al., 2014; Krohn et al., 2014) seem to begin. However, upon closer examination these 'gullies' are the edges of mass-wasting lobes flowing down the crater wall (Fig. 7B). While the northern and southern walls are rubbly, with significant boulders, the slumped eastern wall is smooth.

Like Cornelia, Fabia has both bright and dark ejecta that are visible in both the clear filter and the false color FC data (Fig. 1). However, the Fabia dark ejecta is strongly correlated with the rubbly material associated with the northern and southern crater walls. Analysis of VIR data has revealed that the bright Fabia ejecta are enriched in diogenite (De Sanctis et al., 2014). 
(A)

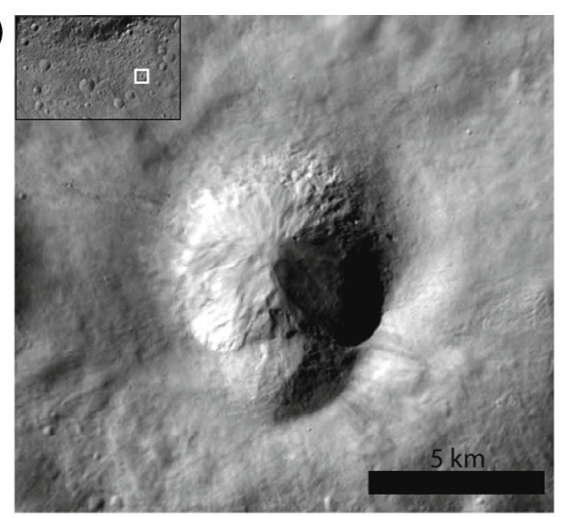

(B)

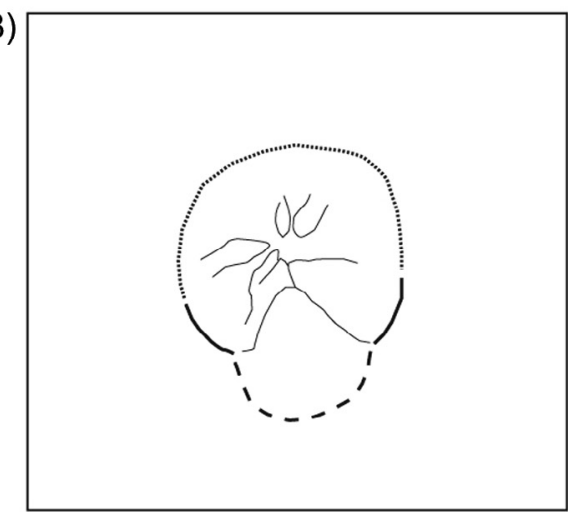

(C)

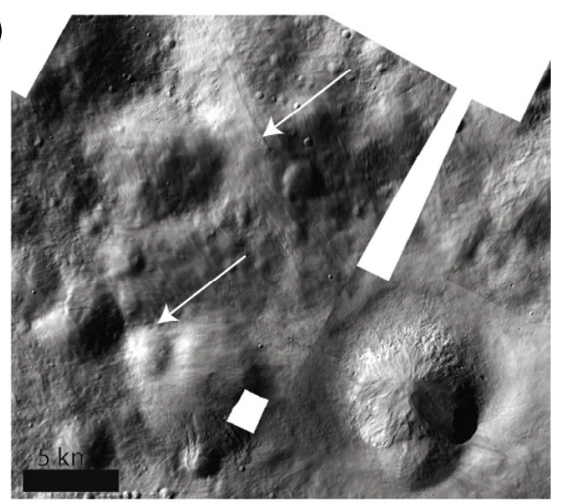

(D)

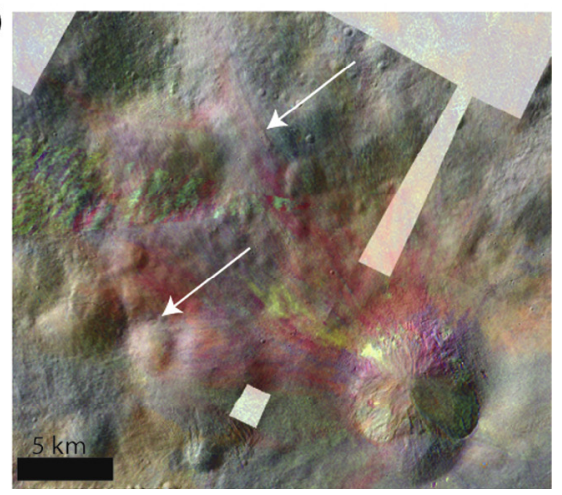

Fig. 6. (A) FC clear filter LAMO mosaic of Teia crater. Inset box shows location of Teia marked by white square on the Av- 9 mosaic. (B) Sketch map of features found within Teia. Thin solid lines outline some of the overlapping mass-wasting lobes on the walls of Teia; only those visible at the resolution of the figure are sketched. Thick dotted line marks a less distinct portion of the crater rim. Dashed line marks the rim of the older crater to the south of Teia. (C) Context image of Teia and its nearby ejecta. White arrows point to examples of the smeared morphology of lineated ejecta. (D) FC color ratio image of Teia draped over clear filter data. White arrows point to same regions of image as in part c. Note that lineated ejecta is associated with areas that the color ratio data indicate are spectrally diverse. (For interpretation of the references to color in this figure legend, the reader is referred to the web version of this article.)
(A)

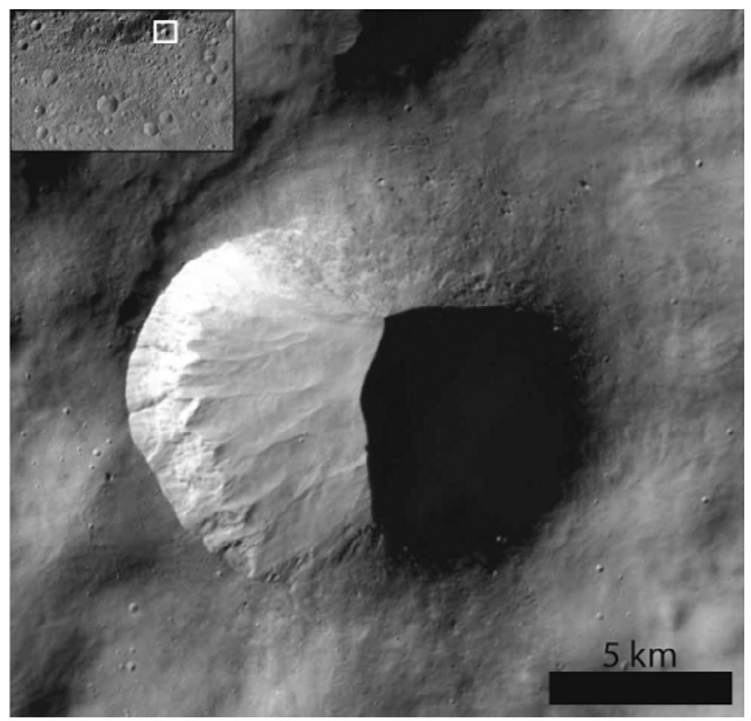

(B)

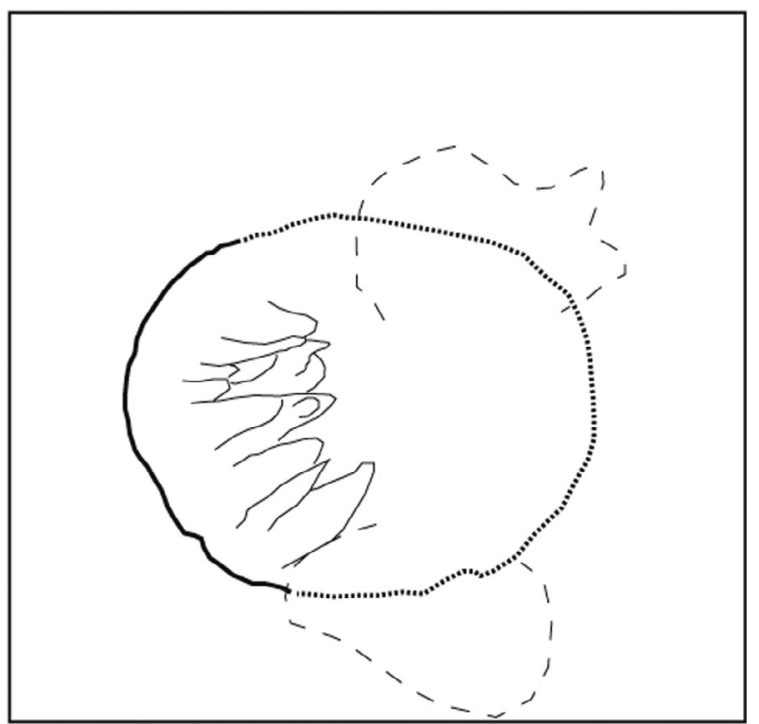

Fig. 7. (A) FC clear filter LAMO mosaic of Fabia crater. Inset box shows location of Fabia marked by white square on the Av-9 mosaic. (B) Sketch map of features found within Fabiaa. Thin solid lines outline overlapping mass-wasting lobes on the walls of Fabia; only those lobes visible at the resolution of the figure are sketched. Thick dotted line marks the slumped portion of the asymmetric crater rim. Dashed lines mark out regions of rubbly material.

\section{4. "Dark ribbon"}

Clearly evident in FC color ratio data of the Av-9 quadrangle is a roughly linear unit of a distinct material crossing Vestalia Terra from the northwest to the southeast (Figs. 1c, and $8 \mathrm{~A}$ and $\mathrm{B}$ ). Referred to as the "dark ribbon", this material is also discernible as having a lower albedo in clear filter data, compared to the surrounding terrain. Dark ribbon material extends from the northwest to the southeast for $259 \mathrm{~km}$ across the Av-9 map area, constrained to a linear topographic low on top of the regionally high Vestalia Terra (Fig. 2). LAMO FC images of the material reveal flow features and linear striations that are in line with the dark ribbon axis, rather than being radial to nearby craters (Fig. 8C), such as the unnamed crater at $\sim 2^{\circ}$ latitude, $\sim 228^{\circ}$ longitude. What appears to be a continuation of the dark ribbon extends for an additional $133 \mathrm{~km}$ southeast of Drusilla crater (Fig. 8A and B), into the Rheasilvia basin and the Av-14 Urbinia quadrangle (Mest, this issue).

The dark ribbon is cut by Numisia crater. As noted in Section 3.2.1, there are dark layers observed at top the Numisia 
(A)
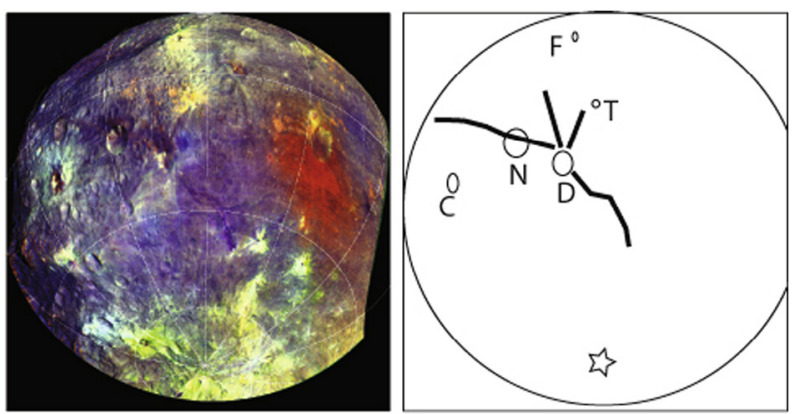

(B)

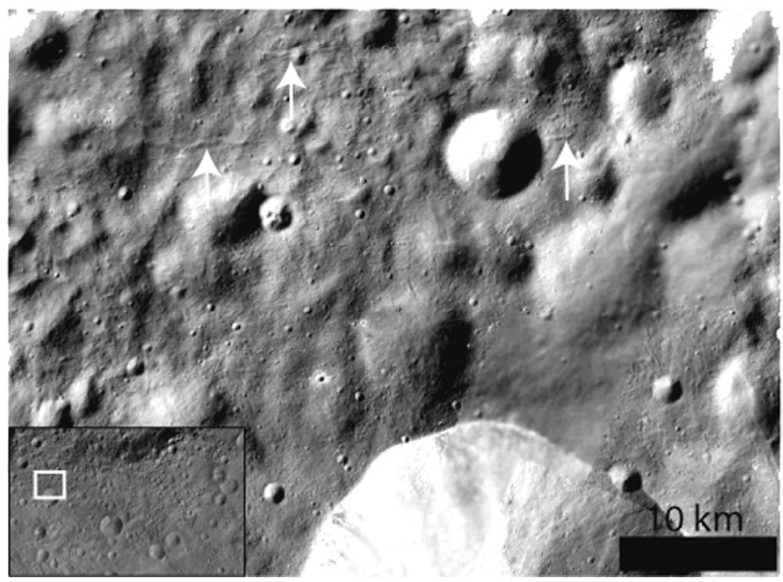

Fig. 8. (A) Global FC color ratio mosaic draped over FC clear filter data, and associated sketch image. Dark ribbon is easily observable in color data and is drawn as thick black line on sketch. Orthographic projection of image enables clear observation of the radial relationship of the dark ribbon to Drusilla crater. Av-9 craters are labeled on sketch image for reference. $\mathrm{D}=$ Drusilla; $\mathrm{N}=$ Numisia $\mathrm{C}=$ Cornelia; $\mathrm{T}=\mathrm{Teia} ; \mathrm{F}=$ Fabia. South pole (star on sketch) is near the bottom of the image. (B) FC clear filter mosaic of dark ribbon just north of an unnamed crater in western Av-9. Inset box shows location, marked by white square on the Av-9 mosaic. White arrows point to flow features that are aligned with the length of the dark ribbon, as opposed to being radial to the crater. (For interpretation of the references to color in this figure legend, the reader is referred to the web version of this article.)

wall, but only in the northern third of the crater (Fig. 3); unlike in both Cornelia and Drusilla craters, the Numisia dark wall material is stratigraphically above the bright wall material (Fig. 3B). Numisia shows a dark layer corresponding to where the crater cuts the dark ribbon, suggesting that the dark layer is in fact the dark ribbon material. Measuring the thickness of the Numisia dark layer, from the top of the crater to the top of the bright layer immediately below suggests that the dark ribbon is approximately $100-250 \mathrm{~m}$ thick in this region.

VIR analysis shows that dark ribbon spectra have the same band centers as the surrounding terrain, but greatly reduced band depths (De Sanctis et al., 2012a). This suggests that the dark ribbon is comprised of material of similar composition but smaller particle size than the underlying terrain, or that the dark ribbon contains a greater admixture of opaque phases than does the surrounding material. While no $\mathrm{OH}$ has been detected in the surface exposures of the dark ribbon, there is $\mathrm{OH}$ detected in the subsurface dark ribbon exposed by Numisia crater (De Sanctis et al., 2012b).

\subsection{Pit crater chains}

While the other equatorial quadrangles on Vesta display the numerous wide and flat-floored troughs of the Divalia Fossa Formation (Df) (Yingst et al., in press), Av-9 does not. As noted by Buczkowski et al. (2012), the equatorial troughs do not cut Vestalia Terra. There are, however, three long pit crater chains roughly aligned with the equatorial flat-floor troughs (Buczkowski et al., 2012) on the plateau.

Pit crater chains are a type of feature that have been observed on several planetary bodies and are described as lines of circular to elliptical depressions which lack an elevated rim, ejecta deposits, or lava flows (Wyrick et al., 2004, 2010). Individual pits most commonly have a conical shape, sometimes with a flat floor, but in some cases they are elliptical in map view, with the long axis parallel to the chain orientation. Pit craters can in many cases coalesce into linear troughs, but the pits are often bordered by a graben ( $a$ down-dropped block bounded by normal faults) even before this coalesence (Wyrick et al., 2004, 2010).

While pits are generally agreed to have formed by collapse into a subsurface cavity (e.g. Thomas et al., 1979; Horstman and Melosh, 1989; Wyrick et al., 2004, 2010), proposed formation mechanisms vary from planet to planet (Wyrick et al., 2010). However, several researchers have suggested that pit crater chains on small bodies such as Phobos (Thomas, 1979), Eros (Prockter et al., 2002; Buczkowski et al., 2008) and Enceladus (Michaud et al., 2008; Martin and Kattenhorn, 2013) are formed by the drainage of a loose cover material into subsurface voids formed by dilation of a steep subsurface normal fault, a mechanism also found applicable to and described in extensive detail for pit crater chains on Mars (Wyrick et al., 2004). This formation hypothesis is strengthened by the strong correlation between pit crater chains and fault-bounded graben that has been observed on Mars and by the fact that pit chains are often in alignment with a regional fault and fracture system (Wyrick et al., 2004).

\subsubsection{Albalonga Catena}

Albalonga Catena is a pit crater chain in eastern Vestalia Terra that is visible both in the Av-8 Oppia and Av-9 Numisia quadrangles. As Albalonga progresses westward into the Av-9 quadrangle it phases from being a $76 \mathrm{~km}$ long series of merged pits (Fig. 9A, black arrows) into an elongate hill that extends $50 \mathrm{~km}$ along its ridgeline (Fig. 9A, white arrow). Individual pit range from 4 to $11 \mathrm{~km}$ in diameter. Westward of the hill, named Brumalia Tholus, another $70 \mathrm{~km}$ linear arrangement of merged pits is visible in the slope data (Fig. 10). These pits range from 2 to $3.5 \mathrm{~km}$ diameter. Given the orientation of the two sets of merged pits and the center line of Brumalia Tholus (Fig. 9C), it is likely that the three features represent a single buried fault.

\subsubsection{Robigalia Catena}

Robigalia Catena is an $89 \mathrm{~km}$ long pit crater chain immediately south of Cornelia crater and within the crater's bright ejecta lobe, suggesting that the Cornelia ejecta is collapsing into the subsurface cavity. The average individual pit ranges from 3 to $5.5 \mathrm{~km}$ in diameter, but there is one relatively large pit $12 \mathrm{~km}$ in diameter. The merged pits show signs of collapse, but distinct fault faces can also be observed (Fig. 9B).

To the south and west of Robigalia is another, smaller pit crater chain (Fig. 9C). This unnamed feature is $36 \mathrm{~km}$ long and the component pits average $2 \mathrm{~km}$ in diameter. Like Robigalia Catena, this pit crater chain outcrops in Cornelia crater's bright ejecta lobe.

\subsection{Brumalia Tholus}

Along its length, Albalonga Catena phases from being a topographically low series of merged pits (Fig. 9A) into the topographically high Brumalia Tholus (Fig. 10). If Albalonga Catena does represent a buried normal fault, as the work of Wyrick et al. (2004) would suggest, then the topographic high that emerges along its length is most likely to have formed as some type of magmatic intrusion. Molten material could have utilized the subsurface 

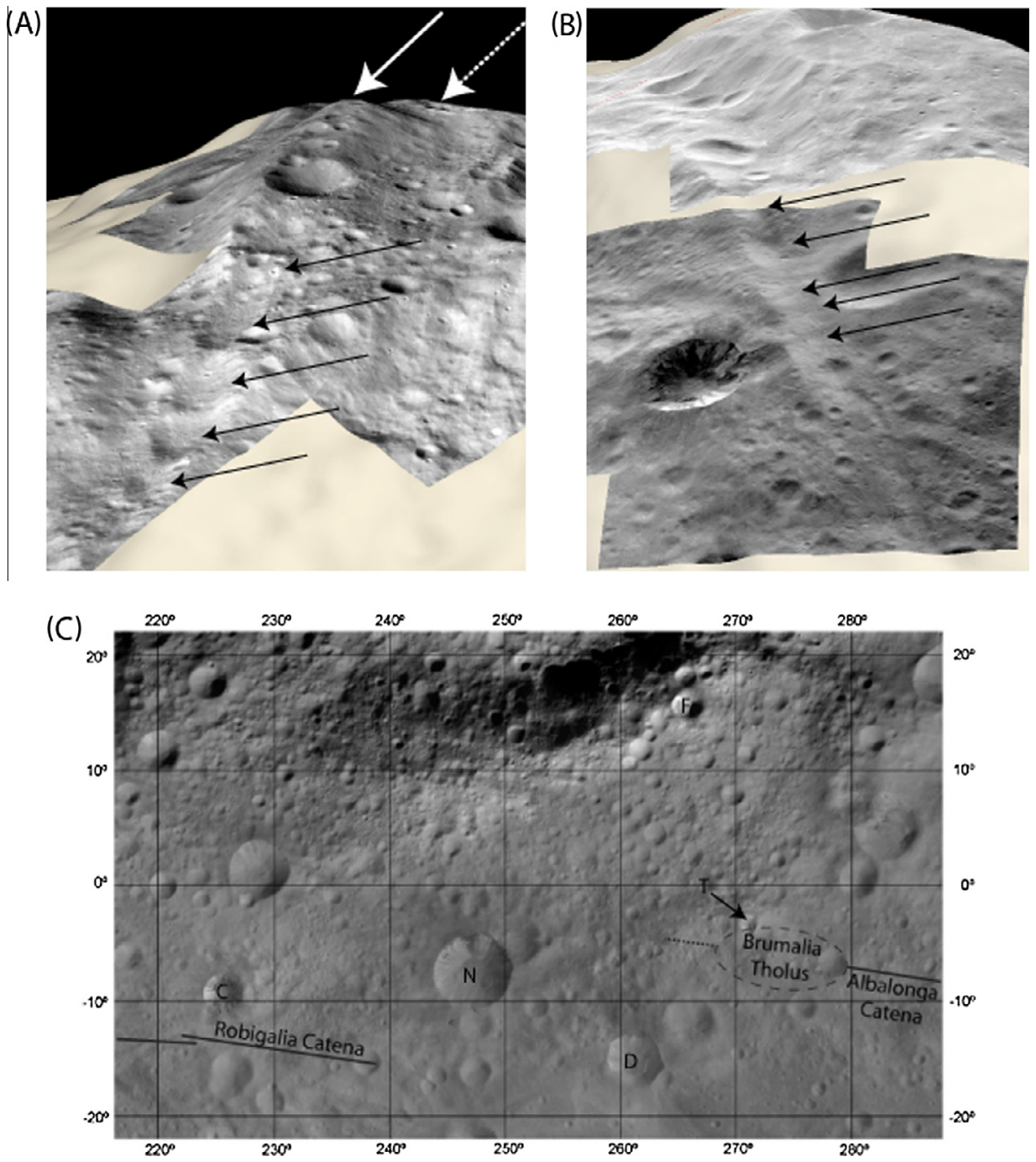

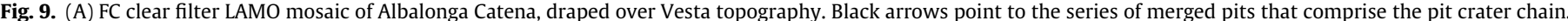

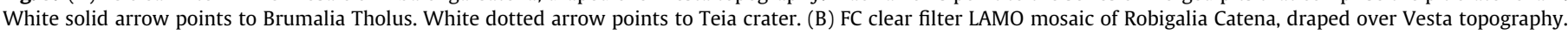

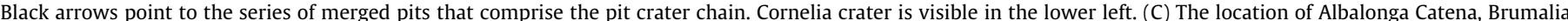

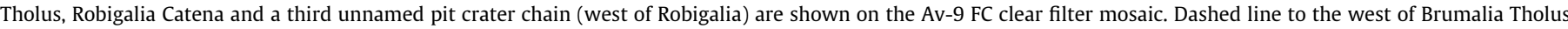
represents the probable extension of Albalonga Catena. Craters names are denoted by: $\mathrm{C}=$ Cornelia; $\mathrm{N}=\mathrm{Numisia}$; $\mathrm{D}=\mathrm{Drusilla}$; Teia $=$ Teia

fracturing as a conduit to travel towards the surface, intruding into the rock above it and deforming it.

Brumalia Tholus is $36 \mathrm{~km}$ wide and $68 \mathrm{~km}$ long, and topographic profiles indicate that it is dome shaped along both the long and short axes. Together with its size, this suggests that Brumalia Tholus could be the surface representation of a laccolith forming over a dike. Laccoliths form when a magmatic intrusion does not reach the surface but magma pressure is high enough to dome the overlying material. If this hypothesis is correct, then the core of Brumalia Tholus would be comprised of a more plutonic rock than the basaltic eucrites and brecciated howardites that have been observed on the majority of the equatorial region of Vesta's surface (De Sanctis et al., 2012a). Since cooling below the surface takes places slowly, larger crystals, such as those observed in diogenites, have time to form.

Teia crater (Fig. 6) formed on the northern face of Brumalia Tholus (Figs. 9A, and 10) and thus its ejecta is likely sampling Brumalia's core material. As is discussed in Section 3.3.1, these Teia ejecta have been found to be more diogenitic in composition than the surrounding background terrain (De Sanctis et al., 2014), supporting the assumption that the core of Brumalia Tholus is diogentic.
DeSanctis et al. (in preparation) also identified diogenitebearing material in small spots inside and along the small craters on the top of Brumalia Tholus. FC color data displays this material as the same false-color red and orange as the Teia ejecta. The identification of diogenite on the top of Brumalia Tholus and in the ejecta of Teia crater is consistent with the hill being the surface representation of a subsurface magmatic intrusion.

\section{Geologic map}

\subsection{Mapping approach, techniques and tools}

The imaging, spectroscopic and topographic data discussed in Section 2 were imported into ArcGISTM 10 software as a basis for our geologic mapping (Fig. 11). Close collaboration was maintained with the mappers of neighboring quadrangles (Williams et al., 2014b; Scully et al., 2014; Kneissl et al., 2014; Garry et al., 2014; Mest et al., this issue) to insure that the unit contacts would match across quadrangle boundaries. Also, every effort was made to develop a consistent level of detail in the mapping effort (Williams et al., 2014a). While the global map was produced 
(A)

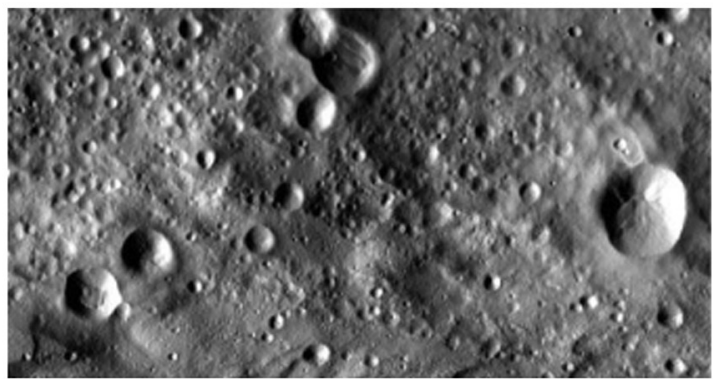

(B)

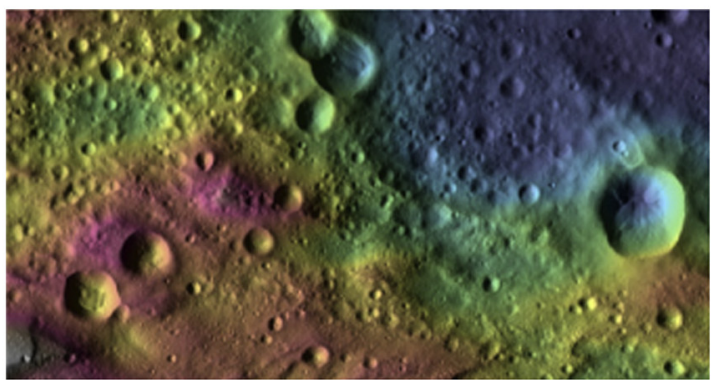

(C)

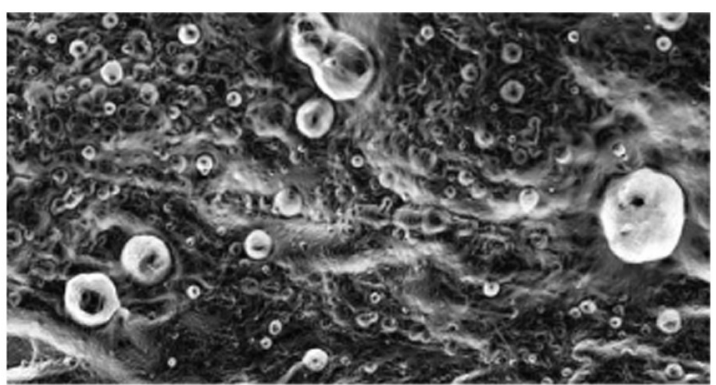

(D)

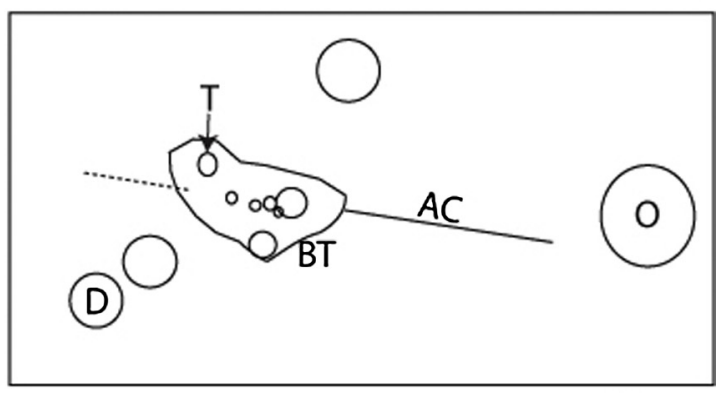

$50 \mathrm{~km}$

Fig. 10. Region of eastern Vestalia Terra showing Brumalia Tholus, from $10^{\circ} \mathrm{N}$ to $20^{\circ} \mathrm{S}$ and 250 to $315^{\circ} \mathrm{E}$. Region shown is over the boundary between the Av-9 and Av-10 quadrangles. (A) Framing camera LAMO mosaic of region. (B) Topography data overlying LAMO mosaic. See Fig. 2 for color bar. (C) Slope data of region. Slopes range from $0.02^{\circ}$ (dark gray) to $38.6^{\circ}$ (white). Albalonga Catena is distinctly visible in this data set. (D) Sketch map of features in region. BT = Brumalia Tholus; $\mathrm{AC}=$ Albalonga Catena; $\mathrm{O}=$ Oppia crater; $\mathrm{D}=$ Drusilla crater; $\mathrm{T}=$ Teia crater. Severa unnamed craters and the probable extension of Albalonga to the west of Brumalia are also depicted. (For interpretation of the references to color in this figure legend, the reader is referred to the web version of this article.)

at a scale of 1:500,000 (Yingst et al., in press), this quadrangle map is at a scale of $1: 250,000$. A correlation of map units (COMU) was also produced (Fig. 12).

\subsection{Map units}

We use the material units and structures produced for the HAMO-based global geologic map of Vesta (Yingst et al., in press), except where updated and modified to take into account the unique features of Av-9 quadrangle.
Vestalia Terra was mapped as cratered highlands material (ch) in the global map of Vesta (Yingst et al., in press). However, the stratigraphic relationships discussed in Sections 3.1 and 5.1 show that Vestalia Terra is older than the rest of the material mapped as cratered highlands. We thus map this material as Vestalia Terra material (vt) to distinguish its unique nature.

To the south and east of the Vestalia Terra material are outcrops of cratered plains material (cp). This material is described by Yingst et al. (in press) as ancient cratered terrain degraded or smoothed by either the emplacement of a layer of Rheasilvia ejecta, or the degradation of sloping material over time. This material fills the Feralia basin but is cut by Saturnalia Fossa A, so an age between the Feralia and Veneneia impacts can be estimated (Fig. 12).

In the northern portion of the quadrangle is an outcrop of the Saturnalia Fossae material (sf) (Yingst et al., in press), defined in the global map as ancient crustal material, heavily disrupted into fault-bounded graben by impact and tectonic processes. While the global map includes non-tectonized regions of northern Vesta in this formation, the northern Av-9 quadrangle covers the tectonized region, including parts of Saturnalia Fossa A, and so is specifically mapped as Saturnalia Fossae trough terrain ( $\mathrm{sft}$ ), following the mapping convention for Vesta's northern hemisphere (Ruesch et al., 2014). This material is on the Postumia basin floor and so is younger than the Postumia impact, but its formation would have ended soon after the Veneneia impact (Fig. 12) that formed the Saturnalia Fossae (Jaumann et al., 2012; Buczkowski et al., 2012).

The global map divided crater material into several different units, including bright crater material (bc), dark crater material (dc) and undifferentiated ejecta material (uc) (Yingst et al., in press). These materials were defined solely by their albedo, not by their composition. Several craters in the Av-9 quadrangle have ejecta blankets with strong albedo contrasts and so were mapped as either bright or dark crater material rather than undifferentiated ejecta material. For example, Cornelia crater's smaller, low albedo inner ejecta lobe is mapped as dark crater material, while the more extensive, high albedo outer lobe is mapped as bright crater material. However, undifferentiated ejecta was mapped in regions of intermediate albedo within the Cornelia, Numisia and Drusilla craters, and in the northwest corner of the map, where there is a continuation of the ejecta around Minucia, Calpurnia and Marcia craters in the Av-8 quadrangle map (Williams et al., 2014b).

The dark material on the floors and in the walls of Cornelia, Numisia and Drusilla craters have been tied to detections of $\mathrm{OH}$ (De Sanctis et al., 2012b). However, only the floor material of Cornelia and Numisia is also pitted (Denevi et al., 2012). We thus map the materials on the Cornelia and Numisia floors as pitted terrain material (pt), following the mapping convention of the Av-8 quadrangle (Williams et al., 2014b). Since the material on the floor of Drusilla and an unnamed crater at $\sim 2^{\circ}$ latitude, $\sim 228^{\circ}$ longitude are not pitted but are distinct from the wall materials, they are mapped as crater interior material. Fabia and another unnamed crater at $\sim 5^{\circ}$ latitude, $\sim 283^{\circ}$ longitude have rubbly ejecta that is low albedo and are also mapped as dark crater material.

Fabia, Cornelia and Drusilla craters all have high albedo ejecta fields that are mapped as bright crater material. There is also bright crater material mapped in the interior of Cornelia, Numisia, Drusilla and Fabia craters. We interpret this intra-crater material to be directly tied to the bright layers observed in these craters and therefore most likely represents the layer material itself, either in situ or as downslope debris. The unnamed crater at $\sim 2^{\circ}$ latitude, $\sim 228^{\circ}$ longitude also has bright crater material mapped in its interior, although it appears to be bright ejecta from the younger Cornelia crater.

Teia crater also has high albedo ejecta, but with a unique texture and composition (see Section 3.3.1). These ejecta textures were not evident in the HAMO imagery. We map these ejecta as 

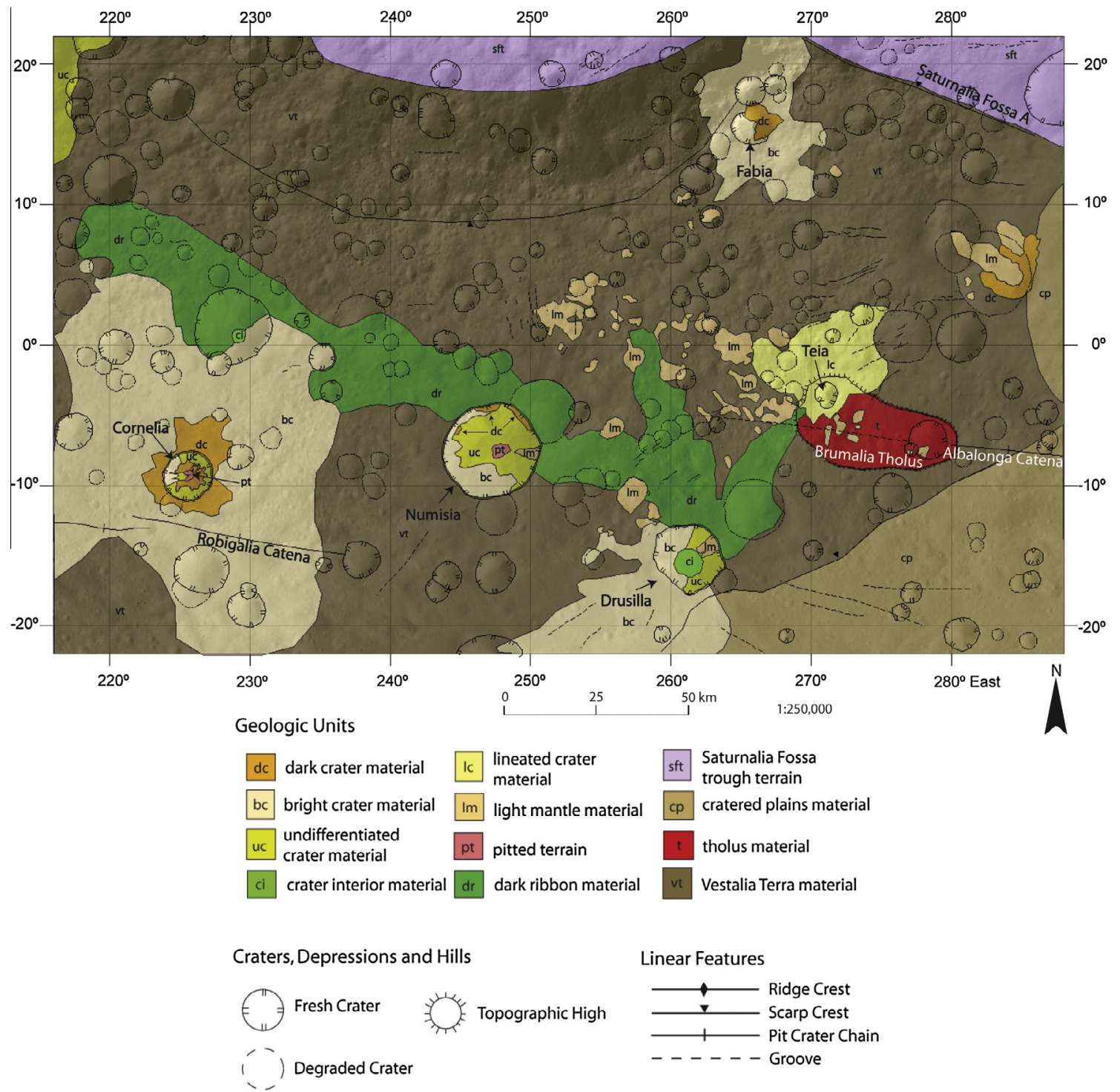

Linear Features

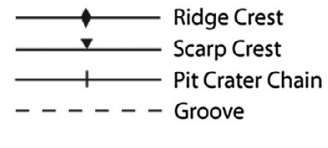

Fig. 11. LAMO-based geologic map of Av-9 Numisia quadrangle. Map units and colors are consistent with HAMO-based global geologic map of Vesta (Yingst et al., in press). (For interpretation of the references to color in this figure legend, the reader is referred to the web version of this article.)

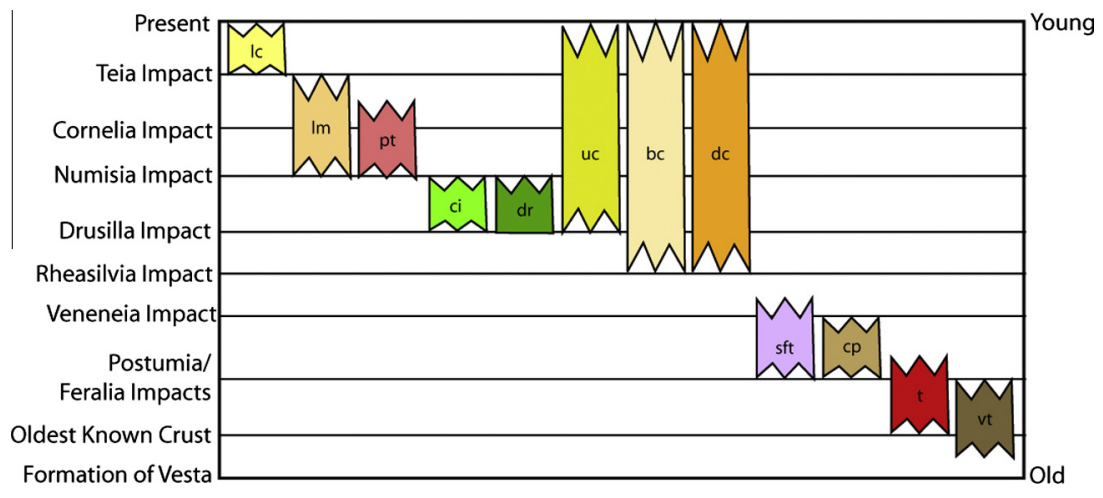

Fig. 12. Correlation of map units (COMU) for the Av-9 Numisia quadrangle geologic map in Fig. 11.

lineated crater material (lc), a unit not recognized in the HAMO global map (Yingst et al., in press). These materials are associated with the false-color yellow and orange in the FC color ratio data (Figs. $1 \mathrm{C}$ and 6D).
The FC color ratio data also reveal other false-color orange deposits in the area that do not share the texture of the lineated crater materials. These light mantle deposits ( $\mathrm{lm}$ ) are prevalent in the adjoining Av-8 quadrangle and may represent ejecta from 
Oppia crater (Garry, 2014). The light mantle material is covered by lineated crater material near Teia crater but overlies dark ribbon material and is found within both the Numisia and Drusilla craters. This indicates that the light mantle material was emplaced prior to the Teia impact but after the Numisia impact (Fig. 12).

Dark lobate material in the global map (Yingst et al., in press) is described as lower albedo materials with lobate margins, relatively smooth surfaces and low topography that extend from crater rims or scarps onto crater floors or local topographic lows and is interpreted as impact-derived material, possibly impact melt. The dark ribbon described in Section 3.4 is a $259 \mathrm{~km}$ long deposit that meets the geomorphic criteria of dark lobate material as it is restricted to a long, linear, topographic low that extends across the top of the Vestalia Terra plateau. However, since many of the lobate and flow features are only observable at LAMO resolution, this outcrop was not included on the HAMO global map. In addition, the dark ribbon is considerably longer and wider than any deposit of dark lobate material in the global map. We therefore map this flow as dark ribbon material (dr), to reflect its unique characteristics. As this material is cut by Numisia crater, it is younger than the Numisia impact (Fig. 12).

Brumalia Tholus is mapped as tholus material ( $t$ ). Tholus material is interpreted to be positive-relief features related to volcanic dikes or intrusions, or volcanic cones (Yingst et al., in press). The identification of Brumalia Tholus as a potential intrusive feature was not known at the time of global mapping and so Brumalia Tholus was not included on the Yingst et al. (in press) map as an outcrop of tholus material.

\section{Discussion}

\subsection{Vestalia Terra as a unique region of Vesta}

Superposition principles suggest that the Vestalia Terra plateau is one of the oldest identifiable features on Vesta. The southeastern boundary of the plateau is defined by the rim of Rheasilvia (Fig. 2B), indicating that the plateau is older than the giant basin $(1.0 \mathrm{Ga}$ in the asteroid flux-derived chronology (Marchi et al., 2012, 2013; O'Brien et al., 2012); 3.59 Ga in the lunar-derived chronology (Schmedemann et al., 2014)). Similarly, the southwestern boundary of Vestalia Terra is defined by the rim of Veneneia. Veneneia itself is superposed by Rheasilvia, and crater counting has confirmed that it is the older basin $(>2.1 \mathrm{Ga}$ in the asteroid flux-derived chronology; $3.39-3.8 \mathrm{Ga}$ in the lunar-derived chronology). To the northeast Vestalia Terra is cut by Saturnalia Fossa $\mathrm{A}$, a large fault-bounded graben whose formation has been tied to the Veneneia impact event (Jaumann et al., 2012; Buczkowski et al., 2012) and has been dated to approximately the same age as Veneneia (Schmedemann et al., 2014). The northern boundary of Vestalia Terra is defined by the Postumia basin which is itself cut by the Saturnalia Fossae, suggesting that this basin is also older than Veneneia. While the floor of Postumia has been dated to $3.78 \mathrm{Ga}$ by Schmedemann et al. (2014), which would imply that it is the same age as Veneneia, it was noted that the deformation of the basin by the fossae would reset the crater count to the date of fossae formation. Similarly, only a minimum age can be derived for Feralia Planitia, which defines the eastern boundary of Vestalia Terra. Feralia underwent an intense resurfacing event, which has been dated to $3.62 \mathrm{Ga}$ (Le Corre et al., 2013). However, since Feralia is also cut by Saturnalia Fossa A we can presume that it too is older than Veneneia. The fact that Vestalia Terra is bounded by these ancient basins indicates that the plateau material itself pre-dates all of them (Fig. 12).

Contrary to these observations, crater counts of the surface material in southern Vestalia Terra suggests an age similar to the other cratered highlands on Vesta $(3.57-3.74 \mathrm{Ga})$ using the lunarderived chronology, comparable to the age of the Rheasilvia basin (Schmedemann et al., 2014). This can be explained by the resurfacing of Vestalia Terra by Rheasilvia ejecta.

The preservation of Vestalia Terra may be due to it being comprised of a stronger material than the rest of Vesta. While the equatorial region of Vesta displays numerous wide, flat-floored troughs whose formation has been tied to the Rheasilvia impact event (Jaumann et al., 2012), these troughs do not cut the Vestalia Terra plateau (Buczkowski et al., 2012). The fact that Vestalia Terra did not fault during this global-scale stress event is consistent with it being comprised of a stronger material.

There are signs of subsurface faulting of the plateau in the three Vestalia Terra pit crater chains (Fig. 9) discussed in Section 3.5. Pit crater chains are hypothesized to form over steep (sub-vertical), dilational segments of buried normal faults (Wyrick et al., 2004) and dilation of normal fault segments occur where the faults cut mechanically strong stratigraphic layers (Ferrill and Morris, 2003; Wyrick et al., 2004). Therefore, the presence of large pit crater chains also suggests that Vestalia Terra must be comprised of stronger and more resistant material than the rest of the asteroid.

Recent work by Raymond et al. (2013) has shown that there is high Bouguer gravity anomaly associated with southern Vestalia Terra. This indicates that Vestalia Terra is composed of a denser material than the rest of Vesta's crust. Raymond et al. (2013) suggests that this density difference is related to the presence of a fossil mantle plume underlying the plateau; in fact, the crustal thickness at southern Vestalia Terra is practically zero (Raymond et al., 2013).

There is also compositional evidence that Vestalia Terra may be comprised of a denser material. The VIR spectra have indicated that Vesta is generally covered by a howarditic regolith, but that the floor of the Rheasilvia basin has a higher diogenitic component while certain equatorial regions contain a greater abundance of eucritic material (De Sanctis et al., 2012a). Given that Rheasilvia is a deep enough impact to have sampled the lower crust (or even the upper mantle) of Vesta (Schenk et al., 2012; McSween et al., 2013) this is consistent with a higher fraction of (slowly cooled) diogenite at depth, reminiscent of the simple layered model of Takeda (1979). However, VIR has detected diogenitic material in the ejecta of some Vestalia Terra craters (De Sanctis et al., 2014). This suggests that under the surface howardite layer, Vestalia Terra is comprised of a denser, plutonic, more diogenitic material, rather than basaltic eucrites.

In addition, the presence of the $\mathrm{OH}$-bearing craters, pitted terrain, and both dark and bright layers in the crater walls reveal more of Vestalia Terra's stratigraphic history. The regions of highest hydrogen concentration on Vesta's surface have been associated with areas of lower-albedo material. The presence of the high-H material is consistent with either the infall of carbonaceous chondrite material onto Vesta (Prettyman et al., 2012b) or emplacement as ejecta from a low-velocity Veneneia impact by a carbonaceous impactor (Reddy et al., 2012b). However, the three $\mathrm{OH}$-bearing craters on Vestalia Terra all display subsurface $\mathrm{OH}$ (De Sanctis et al., 2012b). In Cornelia and Drusilla craters these dark OH-bearing materials are not only subsurface, but lie below a distinct but discontinuous bright layer in the crater's wall (Figs. 4 and 5). The presence of pitted terrain on the floor of Numisia crater suggests that there is $\mathrm{OH}$-bearing material below the bright layers in this crater as well (Fig. 3). If the low albedo OH-enriched layers in the walls of Cornelia, Numisia and Drusilla are carbonaceous chondrite material, then something must have occurred after the emplacement event to cover the deposits with bright material. Furthermore, as the other detections of hydrogen (Prettyman et al., 2012b) and hydroxyl (De Sanctis et al., 2012b) on Vesta are surface deposits, this implies that the bright layer resurfacing event is 
specific to Vestalia Terra. We find that this event is consistent with Vestalia Terra being covered with Rheasilvia ejecta, as these ejecta would have presumably covered any surface dark material. Bright materials on Vesta have been tied to blocks of pyroxene-bearing bedrock (Reddy et al., 2012b) and have been suggested to be ejecta from the Rheasilvia impact by Reddy et al. (2012a). This implies that the stratigraphic history of Vestalia Terra includes resurfacing by both the Veneneia and Rheasilvia impacts, despite the fact that no obvious signs of ejecta (lobe fronts, ejecta scouring, etc.) from these basins were observed.

In summation, the evidence of Vestalia Terra's age, strength and density suggest that it is a unique region of Vesta. The observation of subsurface, as opposed to surface, $\mathrm{OH}$ deposits reinforces the identification of Vestalia Terra as a distinctive locality on Vesta, as no other region appears to have been affected by both Veneneia and Rheasilvia ejecta (Prettyman et al., 2012a,b; Reddy et al., 2012a,b).

\subsection{Formation of Brumalia Tholus}

A structural study of Albalonga Catena and a geomorphic analysis of its orientation relative to the elongate hill Brumalia Tholus suggest that the tholus very likely formed due to surface deformation by a subsurface dike-fed laccolith. Compositional analysis of exposed tholus core materials indicates that they are more diogenitic, and thus plutonic, than the surrounding background material, supporting the laccolith hypothesis.

Several studies assessed the role of igneous intrusion on Vesta prior to Dawn's arrival at the asteroid. Wilson and Keil (1996) suggested that igneous intrusions in the form of dikes could occur on Vesta, based on mathematical and petrological modeling. Their models indicated that both shallow and deep dikes were possible, with volumes between 3 and $10,000 \mathrm{~km}^{3}$. Specifically, they predicted shallow dikes with widths of $\sim 1 \mathrm{~m}$ and vertical extents of $<10 \mathrm{~km}$ and/or deep dikes with thicknesses $3 \mathrm{~m}$ and lateral extents $30 \mathrm{~km}$. In addition, Barrat et al. (2010), who performed a detailed study of the trace-element chemistry of diogenites which suggests that their petrogenesis is more complex than that of simple early crystallization products, proposed that Vesta's diogenites possibly formed as later-stage plutons injected into a eucrite crust. More recently, Keil and Wilson (2012) suggested that there may be many sill-like intrusions at the base of Vesta's lithosphere.

If Brumalia Tholus does represent an igneous intrusion then the source of the melt must be explained. The fact that Brumalia Tholus appears to be diogenitic rather than eucritic (or cumulate eucrite) indicates that the magma that formed this potential intrusion was magnesium rich, and less evolved than typical eucrite.

The Vestalia Terra pit crater chains, including Albalonga Catena, are roughly aligned with the equatorial troughs (Buczkowski et al., 2012), suggesting that their underlying faults may also have formed during the Rheasilvia impact event. Rheasilvia is either $1 \mathrm{Ga}$ or $3.6 \mathrm{Ga}$, depending on whether the asteroid flux-derived crater chronology (O'Brien et al., 2012) or the lunar-derived crater chronology (Schmedemann et al., 2014) is used for dating, but studies of HED meteorites (and simple models of the thermal evolution of asteroidal bodies) suggest volcanism on Vesta ceased by 10-100 Ma after formation, i.e., >4.4 Ga (e.g. Schiller et al., 2010; McSween et al., 2011). Therefore volcanism should have ended long before the time of Rheasilvia impact.

However, it is possible that the Albalonga fault pre-dates the end of Vesta volcanism, and thus that the material that injected the fault could have been sourced by either the magma plume theorized by Raymond et al. (2013) to have formed the Vestalia Terra plateau, from the sill-like intrusions Keil and Wilson (2012) projected to be at the base of the vestan lithosphere or from one of the diogenitic intrusions into eucritic crust predicted by Barrat et al. (2010). While the orientation of Albalonga Catena and the other two Vestalia Terra pit crater chains is roughly consistent with that of the equatorial troughs, it is possible that their underlying faults pre-date the Rheasilvia impact. They could be the result of some earlier impact, such as that which formed the Postumia basin at the northern boundary of Vestalia Terra, or even a result of extension due to the upwelling of Vestalia Terra itself. Their apparent alignment with the equatorial troughs could then be due to small reorientation of the underlying faults after the Rheasilvia impact, similar to that proposed for the southern-most Saturnalia Fossae (Buczkowski et al., 2012).

Another possibility is that the Albalonga faulting did occur due to the Rheasilvia impact event and the putative molten material is diogenitic impact melt associated with the basin's formation. However, while impact melt was expected on the floor of the Rheasilvia basin, to date none has been positively identified (Schenk et al., 2012; McSween et al., 2013), although there is a tentative identification of a small amount within the basin (Williams et al., 2013). It is possible that melt drained through fracturing of the basin floor and due to the peculiarities of the Vestalia Terra plateau was able to inject into the Albalonga fault and deform the surface, forming Brumalia Tholus. However, as it had been previously modeled that melt production on asteroids would be limited due to lower impact velocities (Keil et al., 1997) this seems a less likely source of the molten material.

In either case, it is important to note that the three Vestalia Terra faults most likely formed prior to dike injection, not as a result of the intrusion itself. While dike injection has been shown to sometimes result in overlying graben formation on planetary bodies (e.g. Ernst et al., 2001; Wilson and Head, 2002), in the case of the Vestalia Terra faults only Albalonga is associated with a magmatic intrusion; meanwhile, the orientation of the three pit crater chains relative to each other suggests a common formation mechanism. This strongly implies that the faults pre-date intrusive activity, although not necessarily the broad mantle upwelling hypothesized to form Vestalia Terra (Raymond et al., 2013), and that due to differences in fault depth only Albalonga was deep enough to sample the deep molten material.

We thus suggest that the observations support that the following sequence of events. Ancient fracturing and faulting occured in the Vestalia Terra subsurface, forming the Albalonga, Robigalia and unnamed subsurface faults in the same orientation (Fig. 13a). The Albalonga fault samples a region of partial melt and serves as a conduit for this mantle or lower-crustal material to move upward (Fig. 13b) and deform the surface (Fig. 13c). Brumalia Tholus forms due to magmatic injection and laccolith doming (Fig. 13d). The core molten material cools slowly at depth, forming diogenite. Sometime later the Rheasilvia impact occurs, reactivating (and perhaps reorienting) the Albalonga and other Vestalia Terra faults. The surface of Vestalia Terra is covered by loose regolith material (i.e. ejecta) which collapses into dilational openings along the steep subsurface faults, forming the pit crater chains (Fig. 13e). Then the Teia impact event occurs and incorporates the diogenitic Brumalia core material into its ejecta (Fig. 13f).

\subsection{Origin of the dark ribbon}

An evaluation of lobate flows on Vesta determined that there were no volcanic flows on the asteroid (Williams et al., 2013), and therefore volcanism cannot be an explanation of the dark ribbon. Instead, Williams et al. (2013) found that all lobate flow materials were associated with impact craters or steep slopes, indicating that their formation was either due to impact or erosional mass-wasting processes. This analysis suggests that the dark ribbon is either a result of impact or mass-wasting; further clues as to its origin can be found through an evaluation of the 
(A)

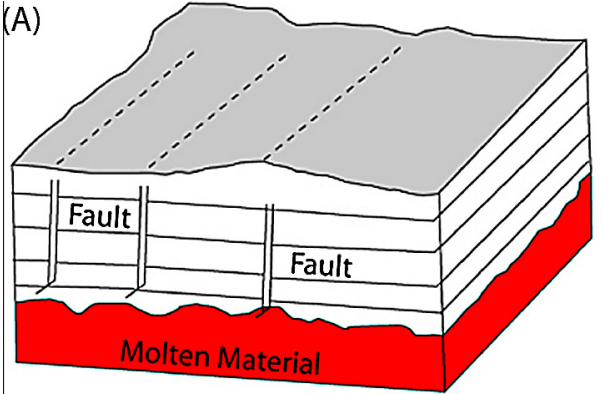

(B)

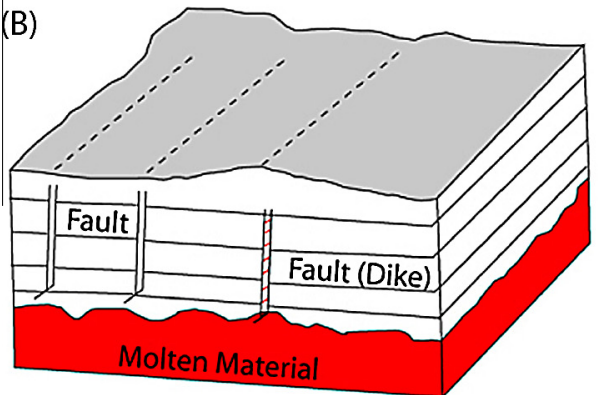

(C)

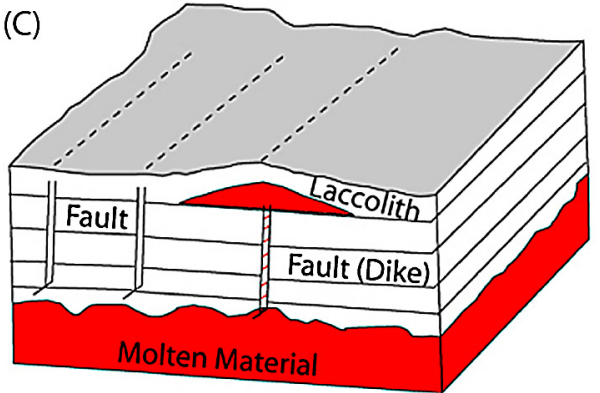

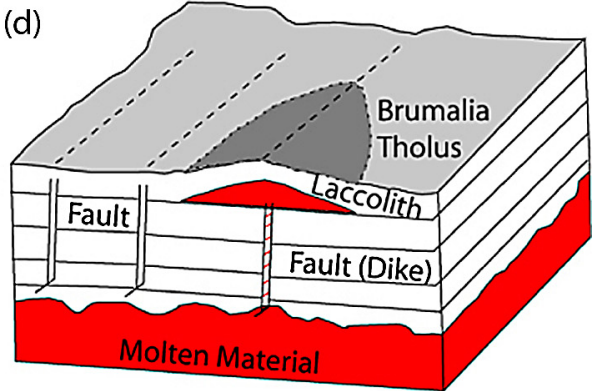

(d)

(E)

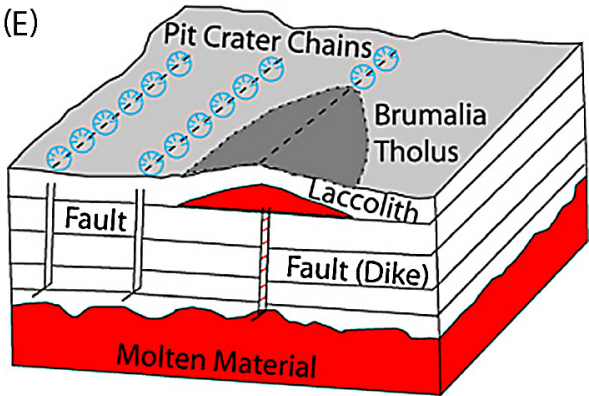

(f)

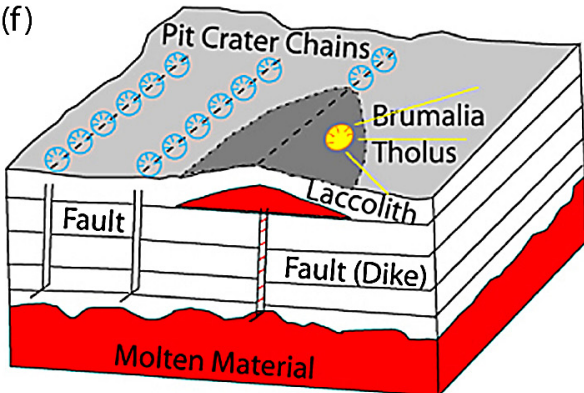

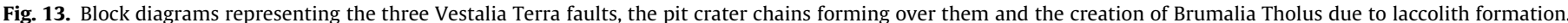

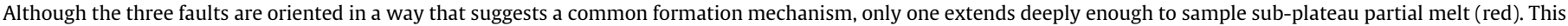

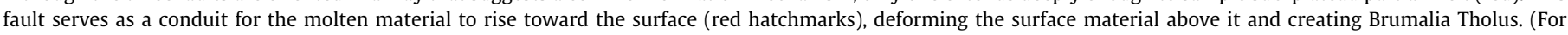
interpretation of the references to color in this figure legend, the reader is referred to the web version of this article.)

Av-9 geologic map, in conjunction with the topographic and compositional data of the region.

As discussed in Section 3.2.3, the ejecta to the north of Drusilla crater has low albedo. This ejecta appears to be radial to the crater, with three distinct fingers of dark material in the Av-9 region (Fig. 1c); a fourth line of dark material extends to the southeast of the crater (Fig. 8A) but does not appear in the geologic map (Fig. 11) because it begins just outside the Av-9 map area. The westernmost lobe of these dark ejecta fingers continues past the length of the other two northern lobes and is the southeastern end of the dark ribbon material (Figs. $1 \mathrm{C}$ and $8 \mathrm{~A}$ ). This suggests that the dark ribbon is in fact Drusilla ejecta. As mentioned in Section 3.4, the VIR analysis shows that dark ribbon spectra have the same band centers as the surrounding terrain, but greatly reduced band depths (De Sanctis et al., 2012b). This reduction in band depth could be a result of reduced particle size of the material, as would be expected in an ejecta deposit relative to the preimpact bedrock. However, while the radial Drusilla ejecta extends only two crater diameters away from the crater, the dark ribbon extends seven crater diameters from Drusilla. Proposing that the dark ribbon is Drusilla ejecta requires additional explanation of how this putative ejecta could travel so far from the source crater in this one, relatively narrow, direction.

We present the possibility that the dark ribbon may represent an ejecta flow bearing entrained gases released during the impact event. It is known that there is $\mathrm{OH}$ in Drusilla crater (De Sanctis et al., 2012b). While the impacts that formed the other hydrogen-bearing craters, Cornelia and Numisia, resulted in pitted terrain (Prettyman et al., 2012b; Denevi et al., 2012), it is possible that the volatiles released during the Drusilla impact were trapped under the ejecta and enabled it to undergo "basal glide" (BarnouinJha et al., 2005), resulting in a long-runout flow. While no $\mathrm{OH}$ has been detected in the surface exposures of the dark ribbon, the spectral signature of $\mathrm{OH}$ has been found in the subsurface dark ribbon exposed by Numisia crater (De Sanctis et al., 2012b); this is consistent with the proposed $\mathrm{OH}$ at the base of the dark ribbon being preserved by its very burial, while any surface $\mathrm{OH}$ would have sputtered off. Furthermore, while the Drusilla ejecta radial to the crater has no correspondence to topography, the dark ribbon extends to the northwest following a local linear topographic low (Fig. 1C). We thereby suggest that the dark ribbon material is ejecta directed into a channelized flow within this "corrugation" on the top of the Vestalia Terra plateau. It was this channelization, in combination with basal glide over impact-released gases, that we propose enabled the dark ribbon to reach such great lengths from its source crater.

The majority of the dark ribbon is slightly off-radial from Drusilla crater (Figs. 1C and 8A) but this can be explained by two observations. If, as suggested, the dark ribbon is entrained ejecta then its flow is controlled by the orientation of the linear topographic low 
that the ejecta traveled along. Therefore the entirety of the dark ribbon does not need to be radial to Drusilla, merely that portion closest to the crater. In addition, the impact of Numisia crater into the dark ribbon material sampled the dark ribbon material and incorporated it into its own ejecta. This re-distribution of dark ribbon material as Numisia ejecta, in addition to the disruption of the dark ribbon by the Numisia cratering event itself, would also contribute to its slight off-radial orientation.

\section{Conclusions}

The Av-9 Numisia quadrangle extends from $\pm 22.5^{\circ}$ latitude and from $216^{\circ}$ to $288^{\circ} \mathrm{E}$ longitude on Vesta (Fig. 1). The geologic map (Fig. 11) is dominated by Vestalia Terra, and analysis of features and relationships within the map region demonstrates that Vestalia Terra is unique on Vesta. Many of the Av-9 impact craters have both bright and dark layers exposed in their walls and spectrally distinct ejecta lobes. Although primarily howarditic, the region does have a diverse composition, with diogenite identified in both small mass-wasting flows and ejecta. In addition, three craters display hydroxyl-bearing materials. The Av-9 mapping supports the hypothesis that the "dark ribbon" feature is a long runout ejecta flow and also aided in the identification of a potential magmatic intrusion on Vesta, Brumalia Tholus. This first evidence for intrusive magmatism on Vesta suggests that even a small planetary body can sustain melting of sufficient volume to intrude into a preexisting crust.

\section{Acknowledgments}

The authors gratefully acknowledge the support of the Dawn Instrument, Operations, and Science Teams. This work was funded by the Dawn at Vesta Participating Science Program, Grant No. NNX10AR58G S06. 'The data used in this paper are available from the website http://dawndata.igpp.ucla.edu. We would also like to thank Brad Thomson and Amanda Nahm for their thoughtful and helpful reviews.

\section{Appendix A. Supplementary data}

Supplementary data associated with this article can be found, in the online version, at http://dx.doi.org/10.1016/j.icarus.2014. 03.035.

\section{References}

Archinal, B.A. et al., 2011. Report of the IAU working group on cartographic coordinates and rotational elements: 2009. Cel. Mech. Dyn. Astron. 109 (2), 101-135. http://dx.doi.org/10.1007/s10569-010-9320-4.

Barnouin-Jha, O.S., Baloga, S., Glaze, L., 2005. Comparing landslides to fluidized crater ejecta on Mars. J. Geophys. Res. 110, E04010. http://dx.doi.org/10.1029/ 2003JE002214.

Barrat, J.A., Yamaguchi, A., Zanda, B., Bollinger, C., Bohn, M., 2010. Relative chronology of crust formation on asteroid Vesta: Insights form the geochemistry of diogenites. Geochim. Cosmochim. Acta 74, 6218-6231.

Bart, G.D., 2007. Comparison of small lunar landslides and martian gullies. Icarus 187, 417-421. http://dx.doi.org/10.1016/j.icarus.2006.11.004.

Beck, A.W., McSween, H.Y., 2010. Diogenites as polymict breccias composed of orthopyroxenite and harzburgite. Meteorit. Planet. Sci. 45 (5), 850-872. http:// dx.doi.org/10.1111/j.1945-5100.2010. 01061.x.

Binzel, R.P., Xu, S., 1993. Chips off of Asteroid 4 Vesta: Evidence for the parent body of basaltic achondrite meteorites. Science 260, 186-191.

Buczkowski, D.L., Barnouin-Jha, O.S., Prockter, L.M., 2008. 433 Eros lineaments: Global mapping and analysis. Icarus 193 (1), 39-52. http://dx.doi.org/10.1016/ j.icarus.2007.06.028.

Buczkowski, D.L. et al., 2012. Large-scale troughs on Vesta: A signature of planetary tectonics. Geophys. Res. Lett.. http://dx.doi.org/10.1029/2012GL052959.

Capria, M.T. et al., 2014. Vesta surface thermal properties map. Geophys. Res. Lett., 41. http://dx.doi.org/10.1002/2013GL059026.
Cedillo-Flores, Y., Treiman, A.H., Lasue, J., Clifford, S.M., 2011. $\mathrm{CO}_{2}$ gas fluidization in the initiation and formation of martian polar gullies. Geophys. Res. Lett. 38, L21202. http://dx.doi.org/10.1029/2011GL049403.

Consolmagno, G.J., Drake, M.J., 1977. Composition of the eucrite parent body: Evidence from rare Earth elements. Geochim. Cosmochim. Acta 41, 1271-1282.

De Sanctis, M.C. et al., 2011. The VIR spectrometer. Space Sci. Rev. 163, 329-369. http://dx.doi.org/10.1007/s11214-010-9668-5.

De Sanctis, M.C. et al., 2012a. Spectroscopic characterization of mineralogy and its diversity across Vesta. Science 336, 697-700. http://dx.doi.org/10.1126/science. 1219270.

De Sanctis, M.C. et al., 2012b. Detection of widespread hydrated materials on Vesta by the VIR imaging spectrometer on board the Dawn mission. Astrophys. J. 758, L36. http://dx.doi.org/10.1088/2041-8205/758/2/L36.

De Sanctis, M.C., Ammannito, E., Buczkowski, D., Raymond, C.A., Jaumann, R., Mittlefehldt, D.W., Capaccioni, F., Capria, M.T., Frigeri, A., Magni, G., Tosi, F., Zambon, F., Russell, C.T., 2014. Compositional evidence of magmatic activity on Vesta, Geophys. Res. Lett., http://dx.doi.org/10.1002/ 2014GL059646 (in press).

Denevi, B.W. et al., 2012. Pitted terrain on Vesta and implications for the presence of volatiles. Science 338 (246). http://dx.doi.org/10.1126/science.1225374.

Drake, M.J., 1979. Geochemical evolution of the eucrite parent body: Possible evolution of Asteroid 4 Vesta? In: Gehrels, T., Matthews, M.S. (Eds.), Asteroids. Univ. of Arizona Press, Tucson, pp. 765-782.

Drake, M.J., 2001. Presidential address: The eucrite/Vesta story. Meteorit. Planet. Sci. 36 (4), 501-513.

Ernst, R.E., Grosfils, E.B., Mege, D., 2001. Giant dike swarms: Earth, Venus and Mars Annu. Rev. Earth Planet. Sci. 29, 489-534.

Ferrill, D.A., Morris, A.P., 2003. Dilational normal faults. J. Struct. Geol. 25, 183-196.

Gaffey, M.J., 1997. Surface lithologic heterogeneity of Asteroid 4 Vesta. Icarus 127 $130-157$.

Garry W.B., et al., 2014. The geology of the Oppia quadrangle of Asteroid (4) Vesta: Determining a relative stratigraphy and establishing a relative geologic timescale through geologic mapping. Icarus 244, 104-119.

Horstman, K.C., Melosh, H.J., 1989. Drainage pits in cohesionless materials: Implications for the surface of Phobos. J. Geophys. Res. 94, 12433-12441.

Jaumann, R. et al., 2012. Vesta's shape and morphology. Science 336, 687-690. http://dx.doi.org/10.1126/ science.1219122.

Keil, K., 2002. Geological history of Asteroid 4 Vesta: The "smallest terrestrial planet”. In: Bottke, W.F., Cellino, A., Paolicchi, P., Binzel, R.P. (Eds.), Asteroids III Univ. of Arizona Press, Tucson, pp. 573-584.

Keil, K., Wilson, L., 2012. Volcanic eruption and intrusion processes on 4 Vesta: A reappraisal. Lunar Planet. Sci. 43. Abstract 1127.

Keil, K., Stoffler, D., Love, S.G., Scott, E.R.D., 1997. Constraints on the role of impact heating and melting in asteroids. Meteorit. Planet. Sci. 32, 349-363.

Kneissl, T., Schmedemann, N., Reddy, V., Williams, D.A., Walter, S., Neesemann, A., Michael, G., Jaumann, R., Krohn, K., Preusker, F., Roatsch, T., Le Corre, L., Nathues, A., Hoffmann, M., Schäfer, M., Buczkowski, D., Garry, W.B., Yingst, R.A., Mest, S. Russell, C.T., Raymond, C.A., 2014. Morphology and formation ages of mid-sized post-Rheasilvia craters - Geology of quadrangle Tuccia, Vesta. Icarus 244, 133157.

Krohn, K., Jaumann, R., Otto, K., Stephan, K., Wagner, R., Buczkowski, D.L., Garry, B. Williams, D.A., Yingst, R.A., Scully, J., De Sanctis, M.C., Kneissl, T., Schmedemann, N., Kersten, E., Matz, K.-D., Pieters, C.M., Preusker, F., Roatsch, T., Schenk, P. Russell, C.T., Raymond, C.A., 2014. Mass movement on Vesta at steep scarps and crater rims. Icarus 244, 120-132.

Le Corre, L., Reddy, V., Schmedemann, N., Becker, K.J., O’Brien, D.P., Yamashita, N., Peplowski, P.N., Prettyman, T.H., Li, J.-Y., Cloutis, E.A., Denevi, B.W., Kneissl, T., Palmer, E., Gaskell, R.W., Nathues, A., Gaffey, M.J., Mittlefehldt, D.W., Garry, W.B., Sierks, H., Russell, C.T., Raymond, C.A., De Sanctis, M.C., Ammanito, E., 2013. Olivine or impact melt: Nature of the "Orange" material on Vesta from Dawn. Icarus 226, 1568-1594. http://dx.doi.org/10.1016/j.icarus.2013.08.013.

Li, J.-Y., 2012. Body-Fixed Coordinate Systems for Asteroid (4) Vesta. <http://sbn. psi.edu/archive/dawn/fc/DWNVFC2_1A/DOCUMENT/VESTA_COORDINATES/ VESTA_COORDINATES_120918.PDF>.

Marchi, S. et al., 2012. The violent collisional history of Asteroid 4 Vesta. Science 336, 690-694.

Marchi, S. et al., 2013. High-velocity collisions from the lunar cataclysm recorded in asteroidal meteorites. Nat. Geosci. 6, 303-307.

Martin, E.S., Kattenhorn, S.A., 2013. Probing regolith depths on Enceladus by exploring a pit chain proxy. Lunar Planet. Sci. 44. Abstract 2047.

McCord, T.B., Adams, J.B., Johnson, T.V., 1970. Asteroid Vesta: Spectral reflectivity and compositional implications. Science 168, 1445-1447.

McSween, H.Y.J., Mittledfehldt, D.W., Beck, A.W., Mayne, R.G., McCoy, T.J., 2011. HED meteorites and their relationship to the geology of Vesta and the Dawn mission. Space Sci. Rev. 163, 141-174. http://dx.doi.org/10.1007/s11214-010-9637-z.

McSween, H.Y et al. 2013. Composition of the Rheasilvia basin, a window into Vesta's interior. J. Geophys. Res. Planets 118, 335-346. http://dx.doi.org/ 10.1002/jgre.20057.

Mest, S.C., 2014. Geologic map of the Av-14 Urbinia quadrangle of Vesta, Supplementary Material. Icarus (this issue).

Michaud, R.L., Pappalardo, R.T., Collins, G.C., 2008. Pit chains on Enceladus: A discussion of their origin. Lunar Planet. Sci. 39. Abstract 1678.

O'Brien, D.P., Marchi, S., Schenk, P., Russell, C.T., Raymond, C.A., 2012. The impact history of Vesta: Developing and testing an absolute cratering chronology. Lunar Planet. Sci. 43. Abstract 2688.

Prettyman, T.H. et al., 2012a. Dawn's gamma ray and neutron detector. Space Sci. Rev. 163, 371-459. 
Prettyman, T.H. et al., 2012b. Elemental mapping by Dawn reveals exogenic $\mathrm{H}$ in Vesta's regolith. Science 338, 242-246. http://dx.doi.org/10.1126/ science. 1225354

Preusker, F. et al., 2012. Topography of Vesta from Dawn FC stereo images. Lunar Planet. Sci. 43. Abstract 2012.

Prockter, L., Thomas, P., Robinson, M., Joseph, J., Milne, A., Bussey, B., Veverka, J. Cheng, A., 2002. Surface expressions of structural features on Eros. Icarus 155 (1), 75-93.

Raymond, C.A. et al., 2013. Vestalia Terra: An ancient mascon in the southern hemisphere of Vesta. Lunar Planet. Sci. Conf. 44. Abstract 2882.

Reddy, V. et al., 2012a. Color and albedo heterogeneity of Vesta from Dawn. Science 336, 700-704.

Reddy, V., Le Corre, L., O’Brien, D.P., Nathues, A., Cloutis, E.A., Durda, D.D., Bottke W.F., Bhatt, M.U., Nesvorny, D., Buczkowski, D., Scully, J.E.C., Palmer, E.M., Sierks, H., Mann, P.J., Becker, K.J., Beck, A.W., Mittlefehldt, D., Li, J.-Y., Gaskell, R. Russell, C.T., Gaffey, M.J., McSween, H.Y., McCord, T.B., Combe, J.-P., Blewett, D., 2012 b. Delivery of dark material to Vesta via carbonaceous chondritic impacts. Icarus 221, 544-559. http://dx.doi.org/10.1016/j.icarus.2012.08.011.

Roatsch, T. et al., 2012. High resolution Vesta High Altitude Mapping Orbit (HAMO) Atlas derived from Dawn framing camera images. Planet. Space Sci. 73 (1), 283286. http://dx.doi.org/10.1016/j.pss. 2012.08.021.

Roatsch, T. et al., 2013. High-resolution Vesta Low Altitude Mapping Orbit Atlas derived from Dawn framing camera images. Planet. Space Sci. 85, 293-298. http://dx.doi.org/10.1016/j.pss.2013.06.024.

Ruesch, O., Hiesinger, H., Blewett, D.T., Williams, D.A., Buczkowski, D., Scully, J., Yingst, R.A., Roatsch, T., Preusker, F., Jaumann, R., Russell, C.T., Raymond, C.A 2014. Geologic map of the northern hemisphere of Vesta based on Dawn FC images. Icarus 244, 41-59.

Russell, C.T. et al., 2012. Dawn at Vesta: Testing the protoplanetary paradigm. Science 336, 684-686.

Schenk, P. et al., 2012. The geologically recent giant impact basins at Vesta's south pole. Science 336, 694-697. http://dx.doi.org/10.1126/ science.1219272.

Schiller, M. Baker, J.A., Bizzaro, M., Creech, J., Irving, A.J., 2010. Timing and mechanisms of the evolution of the magma ocean on the HED parent body. 73rd Ann. Meteor. Soc. Mtg., Abstract 5042. Lunar Planet. Inst. New York.

Schmedemann, N., Kneissl, T., Ivanov, B. A., Michael, G., Wagner, R., Neukum, G., Ruesch, O., Hiesinger, H., Krohn, K., Roatsch, T., Preusker, F., Sierks, H., Jaumann, R., Reddy, V., Nathues, A., Raymond, C. A., Russell, C. T., 2014. The cratering record, chronology and surface ages of (4) Vesta in comparison to smaller asteroids and ages of HED meteorites, Planet. Space Sci. (in press).

Scully, J.E.C. et al., 2014. Sub-curvilinear gullies interpreted as evidence for transient water flow on Vesta. Lunar Planet. Sci. 45. Abstract 1796.

Scully, J.E.C., Yin, A., Russell, C.T., Buczkowski, D.L., Williams, D.A., Blewett, D.T., Ruesch, O., Hiesinger, H., Le Corre, L., Mercer, C., Yingst, R.A., Garry, W.B., Jaumann, R., Roatsch, T., Preusker, F., Gaskell, R.W., Schröder, S.E., Ammannito, E., Pieters, C.M., Raymond, C.A., 2014. Geomorphology and structural geology of
Saturnalia Fossae and adjacent structures in the northern hemisphere of Vesta. Icarus 244, 23-40.

Senthil Kumar, P. et al., 2013. Gullies and landslides on the Moon: Evidence for drygranular flows. J. Geophys. Res. Planets 118. http://dx.doi.org/10.1002/ jgre.20043.

Shinbrot, T., Duong, N.-H., Kwan, L., Alvarez, M.M., 2004. Dry granular flows can generate surface features resembling those seen in martian gullies. Proc. Natl. Acad. Sci. USA 101 (23). http://dx.doi.org/10.1073/pnas.0308251101.

Sierks, H. et al., 2011. The Dawn framing camera. Space Sci. Rev. 163, 263-327.

Takeda, H., 1979. A layered-crust model of a howardite parent body. Icarus 40, 455470.

Takeda, H. 1997. Mineralogical records of early planetary processes on the howardite, eucrite, diogenite parent body with reference to Vesta. Meteorit. Planet. Sci. 32 (6), 841-853.

Thomas, P., 1979. Surface features of Phobos and Deimos. Icarus 40 (2), 223-243.

Thomas, P.C. Veverka, J. Bloom, A. Duxbury, T. 1979. Grooves on Phobos: Their distribution, morphology and possible origin. J. Geophys. Res. 84, 8457-8477.

Tosi, F. et al., 2013. Thermal behaviour of pitted terrains on Vesta. Lunar Planet. Sci. 43. Abstract 1917.

Williams, D.A. et al., 2013. Lobate and flow-like features on asteroid Vesta. Planet. Space Sci. doi: http://dx.doi.org/10.1016/j.pss.2013.06.017i.

Williams, D.A., Denevi, B.W., Mittlefehldt, D.W., Mest, S.C., Schenk, P.M., Yingst, R.A. Buczkowski, D.L., Scully, J.E.C., Garry, W.B., McCord, T.B., Combe, J.-Ph., Jaumann, R., Pieters, C.M., Nathues, A., Le Corre, L., Hoffmann, M., Reddy, V., Roatsch, T., Preusker, F., Marchi, S., Kneissl, T., Neukum, G., Schmedemann, N., Hiesinger, H., De Sanctis, M.C., Ammannito, E., Frigeri, A., Prettyman, T.H., Russell, C.T., Raymond, C.A., and the Dawn Science Team, 2014b. The geology of the Marcia quadrangle of asteroid Vesta: Assessing the effects of large, young craters. Icarus $244,74-88$.

Williams, D.A., Yingst, R.A., Garry, W.B., 2014a. Introduction: The Geologic Mapping of Vesta. Icarus 244, 1-12.

Wilson, L., Head, J.W., 2002. Tharsis-radial graben systems as the surface manifestations of plume-related dike intrusion complexes: Models and implications. J. Geophys. Res. 107 (E8), 1-24. http://dx.doi.org/10.1029/ 2001JE001593.

Wilson, L., Keil, K., 1996. Volcanic eruptions and intrusions on the Asteroid 4 Vesta. J. Geophys. Res. 101 (8), 18927-18940.

Wyrick, D., Ferrill, D.A., Morris, A.P., Colton, S.L., Sims, D.W., 2004. Distribution, morphology and origins of martian pit crater chains. J. Geophys. Res. 109, E06005. http://dx.doi.org/10.1029/2004 JE002240.

Wyrick, D.Y., Buczkowski, D.L., Bleamaster, L.F., Collins, G.C., 2010. Pit crater chains across the Solar System. Lunar Planet. Sci. 41. Abstract 1413.

Yingst, R.A., Mest, S.C., Berman, D.C., Garry, W.B., Williams, D.A., Buczkowski, D. Jaumann, R., Pieters, C.M., De Sanctis, M.C., Frigeri, A., Le Corre, L., Preusker, F. Raymond, C.A., Reddy, V., Russell, C.T., Roatsch, T., Schenk, P.M., 2014. Geologic mapping of Vesta. Planet. Space Sci. doi: http://dx.doi.org/10.1016/ j.pss.2013.12.014 (in press). 